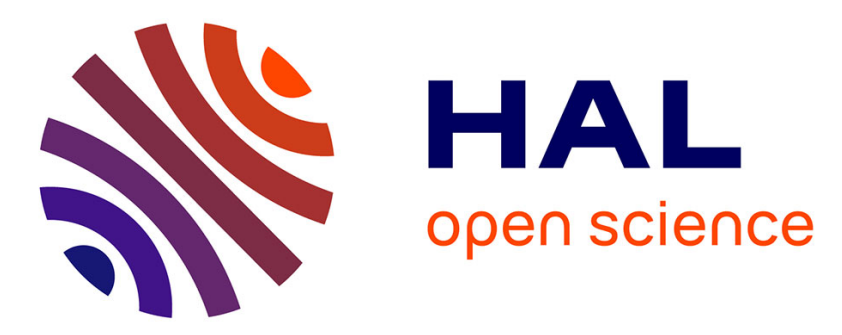

\title{
The dissolution anisotropy of pyroxenes: Experimental validation of a stochastic dissolution model based on enstatite weathering
}

Arnaud Bouissonnié, Damien Daval, François Guyot, Philippe Ackerer

\section{To cite this version:}

Arnaud Bouissonnié, Damien Daval, François Guyot, Philippe Ackerer. The dissolution anisotropy of pyroxenes: Experimental validation of a stochastic dissolution model based on enstatite weathering. Journal of Physical Chemistry C, 2020, 124 (5), pp.3122-3140. 10.1021/acs.jpcc.9b10824 . hal03010516

\author{
HAL Id: hal-03010516 \\ https://hal.science/hal-03010516
}

Submitted on 17 Nov 2020

HAL is a multi-disciplinary open access archive for the deposit and dissemination of scientific research documents, whether they are published or not. The documents may come from teaching and research institutions in France or abroad, or from public or private research centers.
L'archive ouverte pluridisciplinaire HAL, est destinée au dépôt et à la diffusion de documents scientifiques de niveau recherche, publiés ou non, émanant des établissements d'enseignement et de recherche français ou étrangers, des laboratoires publics ou privés. 
1 The dissolution anisotropy of pyroxenes: Experimental validation

\section{2 of a stochastic dissolution model based on enstatite weathering}

3

4 Arnaud Bouissonnié ${ }^{1, *}$, Damien Daval ${ }^{1}$, François Guyot $^{2}$, Philippe Ackerer $^{1}$

5

$6 \quad{ }^{1}$ Université de Strasbourg - CNRS / ENGEES - EOST, Laboratoire d'Hydrologie et de

7 Géochimie de Strasbourg, 1 Rue Blessig, 67084 Strasbourg, France

$8 \quad{ }^{2}$ Institut de Minéralogie, de Physique des Matériaux et de Cosmochimie, Museum National

9 d'Histoire Naturelle, Sorbonne-Université, UMR 7590 CNRS, 61 rue Buffon 75005 Paris,

10 France

11

12 *corresponding author: arnaud.bouissonnie@etu.unistra.fr (A. Bouissonnié)

13 Tel: +33 (0)3 688505 47; Fax: +33(0)368 850402

14 
The understanding of the atomic-scale mechanisms controlling silicate dissolution represents a necessary prerequisite for the success of upscaling exercises aimed at predicting the rates of water-silicate interactions over large space and time scales. In that respect, it has been recently shown that physically-based stochastic models of crystal dissolution at the atomic scale represent a promising alternative to the conventional treatment of silicate dissolution rates, which consists in using empirical rate laws adjusted to the results of powder dissolution experiments. However, most stochastic simulations conducted so far have been based on simple cubic solid structure, and very few were directed to ascertaining the extent to which the simulation outputs quantitatively compare to experimental measurements. In the present study, we take advantage of the anisotropic crystallographic structure and reactivity of chain silicates (pyroxenes) to tackle this issue. Face-specific enstatite dissolution experiments conducted at $\mathrm{pH} 0$ and $90{ }^{\circ} \mathrm{C}$ reveal that the face-specific dissolution rates observe the following trend: $r^{(001)} \gg r^{(210)}>r^{(010)} \geq r^{(100)}$. Electron microscopy characterizations additionally show that lenticular etch pits elongated following the $c$ axis grow on $(h k 0)$ faces, and that nm-thick amorphous Mg-depleted layers cover the reacted enstatite surfaces. A stochastic model was developed, and we show that simulations conducted with bond-breaking probability ratios (and therefore, activation energy differences) that are consistent with the existing literature regarding the hydrolysis of $\mathrm{Mg}-\mathrm{O}-\mathrm{Mg}, \mathrm{Mg}-\mathrm{O}-\mathrm{Si}$ and $\mathrm{Si}-\mathrm{O}-\mathrm{Si}$ bonds can quantitatively account for the measured dissolution rates. In addition, the lenticular shape, the orientation and the symmetry of the pits generated numerically on $(h k 0)$ faces are also consistent with those observed experimentally, while predicting the formation of Mg-depleted surface layers. As a consequence, this study provides a first milestone to the application of stochastic simulations to investigate the dissolution of pyroxenes. 
$40 \quad$ Abstract graphic

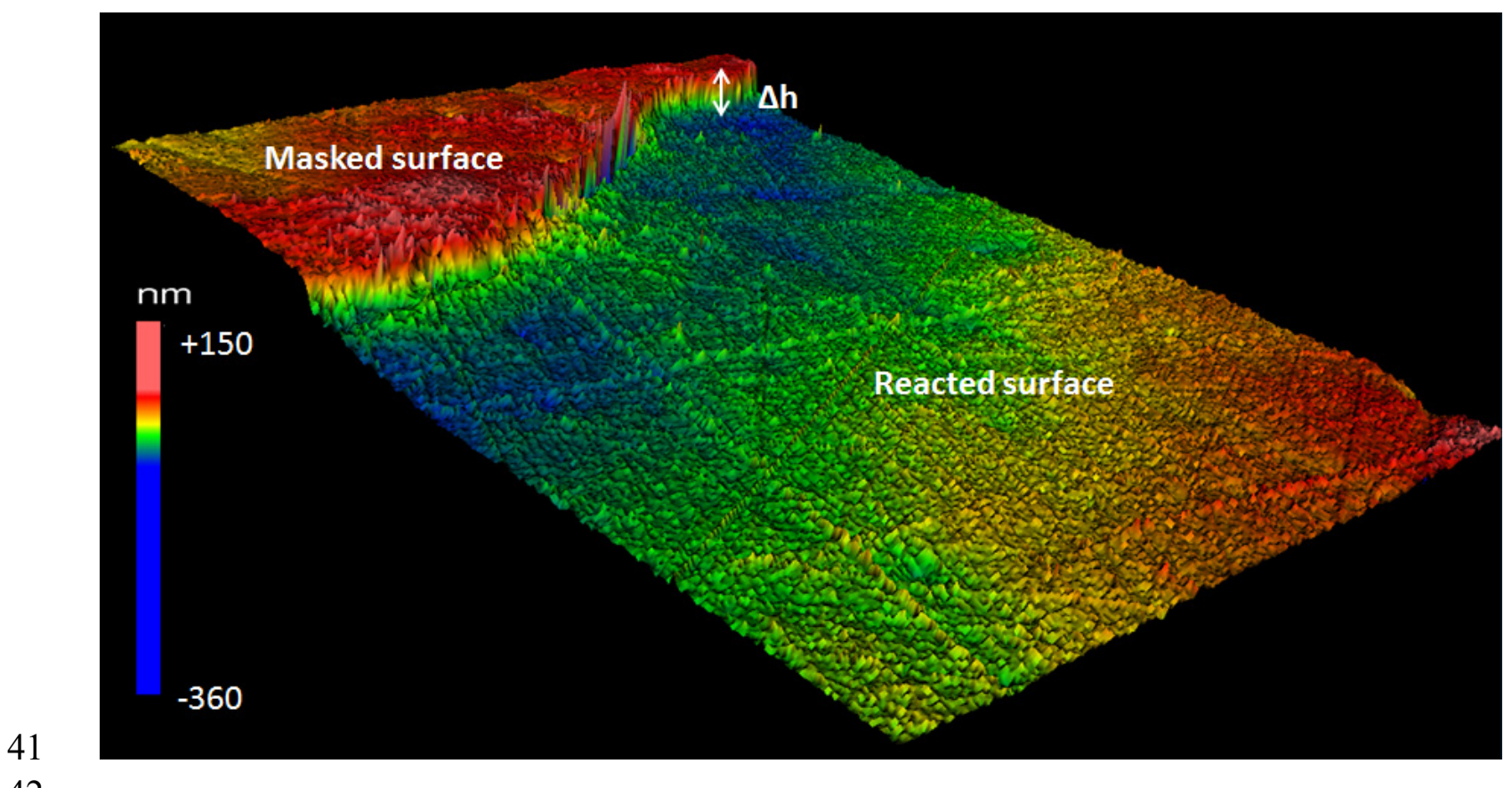

42 


\section{Introduction}

The interactions between aqueous fluids and silicates play a central role in many major geological, environmental and industrial processes. Silicate dissolution and precipitation reactions control on various space and time scales many aspects of the continental surfaces such as providing nutrients to living organisms ${ }^{1}$, participating to the surface water chemistry, mobilizing ${ }^{2}$ or sequestrating natural and anthropic contaminants ${ }^{3}$, shaping landscapes ${ }^{4}$ and ultimately regulating the long-term carbon cycle and climate ${ }^{5-6}$. On an equal footing, predicting the reactivity of silicate surfaces is further important for industrial purposes, such as cement hydration ${ }^{7-8}$ and kinetics of catalyzed reactions ${ }^{9}$. As a consequence, the dissolution rates of silicates have now been investigated for more than half a century, giving rise to a dense body of literature (e.g. Brantley et al. ${ }^{10}$ for a review).

From a mechanistic standpoint, the conventional treatment of mineral reactivity has long been based on the fundamental assumption that silicate dissolution may be described within the framework of the transition state theory (TST), early developed by Eyring ${ }^{11}$ for elementary and homogeneous reactions. The extension of TST by Aagaard and Helgeson ${ }^{12}$ to heterogeneous fluid-solid reactions supposes that silicate dissolution reactions are controlled by a unique rate-limiting step, implicitly requiring that the surface reactivity is homogeneous, isotropic and immutable for a given fluid composition ${ }^{13}$. Although the resulting 'kinetic rate laws' have been implemented into reactive transport codes for several decades, an increasing number of studies has consistently challenged this conceptual framework:

First, it has been theoretically and experimentally demonstrated that mineral reactivity is highly heterogeneous, resulting from the distribution of reactive sites at the fluid-solid interface $^{14}$. The 'rate spectra' concept ${ }^{15}$, which provides a measurement of the rate distribution at the mineral surface in the spatial domain, was developed to indirectly capture this energetic landscape. 
Second, the advent of nanoscale imaging of surface topography has resulted in the demonstration that crystal dissolution is a highly anisotropic process ${ }^{8,16-24}$. These studies showed that the anisotropic reactivity of minerals results from the anisotropic distribution of atomic positions in the crystal lattice, and may be described in the framework of the periodic bond chain (PBC) theory ${ }^{25}$. This theory suggests that crystal faces may be sorted following the number of chains of energetically strong bonds (PBCs) they contain, with the faces containing the largest numbers of PBCs dissolving slower, and vice versa. Pollet-Villard et al. ${ }^{21}$ further proposed that the recognition of the anisotropy of crystal reactivity challenged the idea of a unique relation between the overall dissolution rate of a crystal and the Gibbs free energy of reaction $(\Delta G)$, which is constitutive of the TST formulation, while questioning the existence of a unique intrinsic dissolution rate constant for crystals.

Finally, silicate dissolution is accompanied with gradual physicochemical and structural modifications of their surface, resulting in the formation of nm- to $\mu \mathrm{m}$-thick silica-rich surface layers $^{26-31}$. Accounting for the transport properties of such layers, especially when developed under mildly aggressive conditions (circum-neutral $\mathrm{pH}$, low temperature), was also proposed to be essential to develop reliable models of silicate dissolution ${ }^{23,32}$.

In a nutshell, all these studies converge towards the same conclusion: providing a better theoretical description of mineral dissolution crucially requires gaining knowledge on the relation between the atomic configuration of (and therefore, the energetic distribution at) the dissolving mineral surface and the overall dissolution rate of a given crystal.

Driven by this assertion, studies dedicated to the molecular-scale description of the silicate dissolution process following ab initio quantum mechanical calculations emerged some 20 years ago ${ }^{33-38}$. Such studies shed light on essential theoretical information regarding the dissolution process such as suggesting reaction paths, determining transition state configurations (i.e., bond lengths and angles) and calculating activation energies of the 
hydrolysis reactions in various $\mathrm{pH}$ domains. They also independently confirmed that the dissolution process cannot be boiled down to the kinetics of a single surface reaction. Actually, the large number of possible configurations of dangling atoms at the silicate surface over the course of the dissolution translates into as many possible different hydrolysis reactions, justifying the need for specific numerical simulations of the dissolution process at a scale exceeding clusters of a few atoms. This was precisely one of the motivations for the development of kinetic models using a Monte Carlo approach (often abbreviated as kMC) ${ }^{9,22,}$ 39-47, whose parametrization may strongly rely on the results of $a b$ initio calculations mentioned above. However, with the noticeable exception of a few recent studies $^{9,22,45}$, to date, most of these modelling studies were conducted with simple Kossel crystals ${ }^{48}$, making difficult the direct comparison of the outputs of the simulations with experimental data.

In the present study, we combined experimental measurements of the anisotropy of silicate dissolution (face-specific topographic features and dissolution rates) with stochastic simulations to critically assess the validity of a simple dissolution model. Because of its very anisotropic crystallographic structure made of chains of silica tetrahedrons running parallel to one of the main crystallographic axes, pyroxene was chosen as a case study. It was previously shown that the anisotropic structure of this family of silicates (also known as inosilicates) resulted in a strong anisotropy of dissolution ${ }^{18,23,49}$, intensifying the differences of reactivity between the various faces that define their usual crystal habit. Owing to its simple chemical composition $\left(\mathrm{MgSiO}_{3}\right)$ and structure (orthorhombic), enstatite was chosen as a model within the pyroxene group.

After a brief description of the methods used and the ensuing information, we will discuss the experimental results (i.e., the anisotropy of enstatite dissolution rates and surface features observed using electron microscopy) in regard of pre-existing studies based on pyroxene dissolution. These results will then be compared to the outputs of the simulations, 
118 which will lead to a validation of the dissolution model and a discussion of the wider

119 implications and conclusions for pyroxene dissolution and dissolution mechanisms at the 120 fluid-silicate interface.

\section{Materials and methods}

\subsection{Starting materials and preparation}

The enstatite samples used in this study come from Kilosa (Tanzania), and were supplied by Mawingu Gems Company. Negligible amounts of clinoenstatite (around a few wt. \%) were detected using X-ray diffraction (Fig. S1). Monolithic enstatite samples (up to several tens of $\mathrm{mm}$ on a side) were cut with a diamond blade saw and polished down to the nanometer scale through a multi-step abrasive sequence. The crystallographic orientation of each sample was determined using an electron backscatter diffraction (EBSD) detector attached to a scanning electron microscope (SEM) (TESCAN® Vega 2). The initial roughness of each surface was measured at different scales with vertical scanning interferometer (VSI; ZYGO® NewView 7300). For each sample, the initial average arithmetic roughness $(R a)$, defined as the arithmetic average of the absolute values of the roughness profile, ranged between $5 \mathrm{~nm}$ and

$13415 \mathrm{~nm}$, and $R q$ (the roughness calculated with the root-mean-square of the vertical distance 135 between the surface elevation and the mean surface line) ranged between $19 \mathrm{~nm}$ and $70 \mathrm{~nm}$.

136 These initial roughness parameters were measured on $270 \times 360 \mu \mathrm{m}^{2}$ images obtained using 137 VSI.

\subsection{Dissolution experiments and analytical procedures}

Oriented samples were mounted in a passivated titanium support as designed by Daval et

140 al. ${ }^{18}$, where a Viton ${ }^{\circledR}$ disk held with a screw creates a non-wetted reference area. Partially 141 masked samples were dissolved in a synthetic acidic solution in 120 ml-PFA reactors at $90{ }^{\circ} \mathrm{C}$ 
142 for durations ranging from 6 hours to 3 weeks to check for the linearity of the surface retreat

143 as a function of time.

144 The aqueous solutions were made with ultrapure deionized water (18.2 M $\Omega . \mathrm{cm})$ and

145 analytical grade nitric acid. The $\mathrm{pH}$ was adjusted to $0.0 \pm 0.2$. Nitric acid was chosen to avoid

146 the dissolution of the titanium support that was observed in preliminary tests conducted with

147 hydrochloric acid under similar conditions. Solution sampling was regularly carried out for

148 the analyses of $\mathrm{Si}, \mathrm{Mg}$ and Fe using ICP-AES (Thermo ICAP 6000). The CHESS code ${ }^{50}$ was

149 used to determine the in situ $\mathrm{pH}$ and saturation indices with respect to enstatite and secondary

150 phases. It was verified that all solutions were undersaturated with respect to any secondary

151 phase.

152 For each orientation, at least two solid samples were analyzed for topography

153 measurements. While the first one was periodically recovered to perform the analyses and put

154 back in reactor, the second sample was left in the reactor all over the duration of the

155 experiment. This protocol was followed to make sure that the reactivity of samples that

156 experience wetting/drying cycles to get time-resolved topography measurements remains

157 similar to the reactivity of samples continuously immersed in solution. The topography

158 measurements were performed using VSI in stitching mode (magnification: $\times 5$ ) to estimate

159 the average changes in height between the unreacted reference surface and the reacted mineral

160 surface. For each oriented sample, dissolution rates were calculated according to the

161 following equation (see e.g. Lüttge et al. ${ }^{51}$ ):

$$
r_{\exp }^{(h k l)}=\frac{\Delta h}{\Delta t} \bar{V}^{-1}
$$

162 where $r_{\text {exp }}^{(h k l)}\left(\mathrm{mol} \cdot \mathrm{m}^{-2} \cdot \mathrm{s}^{-1}\right)$ is the dissolution rate of the $(h k l)$ face, $\Delta h$ is the surface retreat $(\mathrm{m})$,

$163 \Delta t$ is the alteration duration (s) and $\bar{V}\left(\mathrm{~m}^{3} \cdot \mathrm{mol}^{-1}\right)$ is the molar volume of enstatite. As detailed

164 below, the minute lateral extension of etch pits ( a few tens of $\mathrm{nm}$ ) prevented the

165 investigation of individual pits by VSI even at high magnification $(\times 100$; lateral resolution 
$166300 \mathrm{~nm}$ ), rendering impossible more sophisticated treatment of the surface topography using e.g. rate spectra.

After completion of the surface topography measurements, the formation of nm-thick, amorphous Si-rich layers (ASSL) was verified to make sure that the layer thickness was negligible compared to the corresponding surface retreat measured by VSI. The samples were

171 either platinum- or carbon-coated and thin sections perpendicular to the investigated faces

172 were prepared by focused ion beam (FIB) milling using the FEI Helios 600 Nanolab dual173 beam operating at CP2M (Marseille, France). The FIB Ga ion milling was carried out at an 174 ion beam voltage of $30 \mathrm{kV}$ and with beam currents from $3 \mathrm{nA}$ to $10 \mathrm{pA}$ for the final steps. 175 Micrometer-thick sections were lifted out in situ using an Omniprobe 200 micromanipulator 176 and transferred to a half copper grid for final ion milling to electron transparency (final 177 thickness of about $100 \mathrm{~nm}$ ). High-resolution transmission electron microscopy (HRTEM) and 178 scanning transmission electron microscopy (STEM) observations were performed on FIB 179 foils using a JEOL 2100F microscope operating at $200 \mathrm{kV}$, equipped with a field emission 180 gun. Energy dispersive X-ray (EDX) spectra were acquired in STEM mode to probe the 181 chemical compositions, with a focused electron beam $(1 \mathrm{~nm})$. When the FIB thin section 182 intersected etch pits (i.e., for the (100) and (010) samples), TEM was further used to 183 characterize their morphologies.

\subsection{Modeling strategy}

The stochastic approach for mineral dissolution studies has emerged in the mid- 80 ' $\mathrm{s}^{52}$.

186 Since then, numerous studies have used stochastic simulations to describe mineral dissolution

187 at the atomic scale, principally using simple Kossel crystals ${ }^{43}$, $47-48$ (simple cubic crystal 188 lattice; 6-fold coordinated atoms) but some have also applied them on more complex mineral ${ }^{9}$, 18922,41 and glass ${ }^{40,44,53}$ structures. These studies have shown the robustness of these models 
190 through their ability to reproduce etch pit shapes ${ }^{9,22}$ and sometimes, by comparing modeled

191 and measured dissolution rates ${ }^{22}$.

192

These models are based on a simple relation that links the bond-breaking probability

193 to the activation energy of the hydrolysis of this bond ${ }^{52}$ :

$$
P=e^{\frac{-\Delta E_{a}}{k_{B} T}}
$$

194 where $P$ is the bond-breaking probability, $\Delta E_{a}$, the activation energy $(\mathrm{J}), k_{B}$, the Boltzmann 195 constant $(\mathrm{J} / \mathrm{K})$ and $T$ the temperature $(\mathrm{K})$.

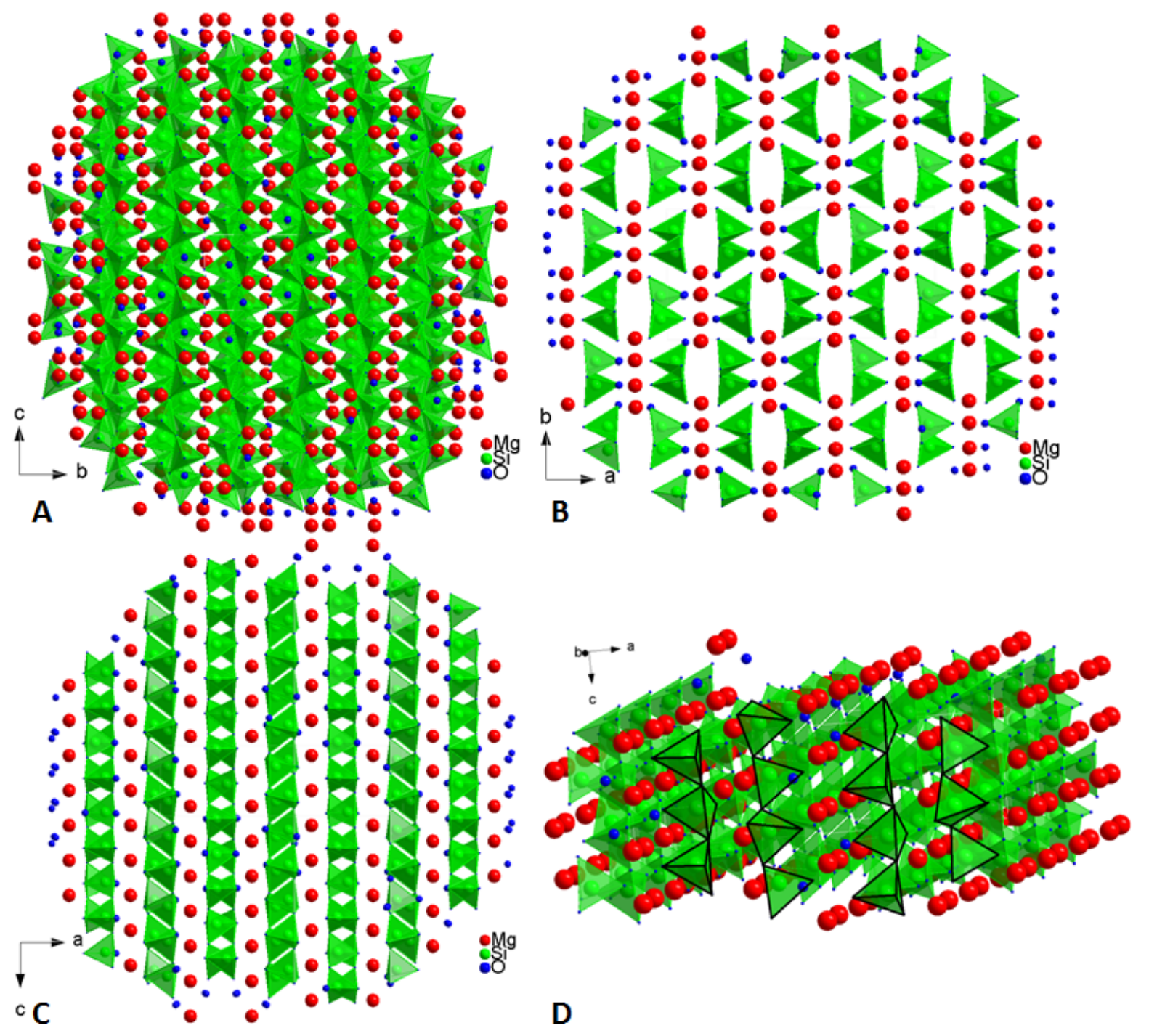

197 Fig. 1. Projection of enstatite structure following [100] (A), [001] (B), [010] (C) zone axes and a rotation view of

198 the enstatite volume (D) to highlight the chains of silicate tetrahedrons. The $\mathrm{Mg}, \mathrm{Si}$ and $\mathrm{O}$ atoms are represented

199 by red, green and blue spheres respectively. Si tetrahedrons are represented in light green. 


\subsubsection{Modeling enstatite crystal structure}

Enstatite is an inosilicate made of chains of silicate tetrahedrons running parallel to the $c$ -

203

204 corresponding to the Pbca system:

$\begin{array}{ccc}\mathrm{x} & \mathrm{y} & \mathrm{z} \\ 1 / 2-\mathrm{x} & 1 / 2+\mathrm{y} & \mathrm{z} \\ \mathrm{x} & 1 / 2-\mathrm{y} & 1 / 2+\mathrm{z} \\ 1 / 2+\mathrm{x} & \mathrm{y} & 1 / 2-\mathrm{z} \\ -\mathrm{X} & -\mathrm{y} & -\mathrm{z} \\ 1 / 2+\mathrm{x} & 1 / 2-\mathrm{y} & -\mathrm{z} \\ -\mathrm{X} & 1 / 2+\mathrm{y} & 1 / 2-\mathrm{z} \\ 1 / 2-\mathrm{x} & -\mathrm{y} & 1 / 2+\mathrm{z}\end{array}$

207 The lengths of the $a, b$ and $c$ axes are $18.233,8.8191$ and $5.1802 \AA$ respectively and the 208 angles $\alpha, \beta$ and $\gamma$ are equal to $90^{\circ}$ (orthorhombic system).

The enstatite unit cell was created based on these parameters, and is composed of 16

210 atoms of magnesium, 16 atoms of silicon and 48 atoms of oxygen. The cell is then repeated

211 following the three space dimensions in order to get a simulated crystal of several tenths to

212 hundreds of nanometers on a side.

$\mathrm{Mg}$ and $\mathrm{Si}$ atoms were connected to $\mathrm{O}$ atoms according to the following rules: (i) $\mathrm{Mg}$ 214 atoms are located in octahedral sites and $\mathrm{Si}$ atoms in tetrahedral sites (i.e., $\mathrm{Mg}$ atoms are 215 connected to $6 \mathrm{O}$ atoms and $\mathrm{Si}$ atoms are connected to $4 \mathrm{O}$ atoms) and (ii) the closest $\mathrm{O}$ atoms 216 were considered to create the coordination spheres surrounding each cation. The resulting 217 modeled surfaces ((100), (010) and (001)) are shown in Fig. 1. 


\begin{tabular}{cccc}
\hline Atoms & $\mathrm{x} / \mathrm{a}$ & $\mathrm{y} / \mathrm{b}$ & $\mathrm{z} / \mathrm{c}$ \\
\hline $\mathrm{Mg} \mathrm{1}$ & 0.3763 & 0.6541 & 0.8663 \\
$\mathrm{Mg} \mathrm{2}$ & 0.3769 & 0.4872 & 0.3589 \\
$\mathrm{Si} \mathrm{1}$ & 0.2715 & 0.3418 & 0.0506 \\
Si 2 & 0.4736 & 0.3374 & 0.7981 \\
O 1 & 0.1835 & 0.3407 & 0.0340 \\
O 2 & 0.3114 & 0.5029 & 0.0430 \\
O 3 & 0.3025 & 0.2224 & 0.8320 \\
O 4 & 0.5622 & 0.3414 & 0.7980 \\
O 5 & 0.4324 & 0.4836 & 0.6900 \\
O 6 & 0.4483 & 0.1951 & 0.6030 \\
\hline
\end{tabular}

Table 1. Atomic coordinates in enstatite cell ${ }^{54}$ used in Eq. (3) to form the entire cell.

\subsubsection{Bond-breaking probabilities}

Most stochastic simulations performed at the atomic scale on silicate materials consider the cleavage of $\mathrm{M}-\mathrm{O}-\mathrm{M}$ bonds instead of single $\mathrm{M}-\mathrm{O}$ bonds ${ }^{9}$. Hence, the oxygen atoms are only considered as bridges between two cations $(\mathrm{Obr})$, and the cations connected to the oxygens of a specific $\mathrm{Si}$ or $\mathrm{Mg}$ atoms are referred to as their first coordination spheres ${ }^{9}$. In enstatite, three types of bonds exist: $\mathrm{Mg}-\mathrm{Obr}-\mathrm{Mg}, \mathrm{Mg}-\mathrm{O} b r-\mathrm{Si}$ and $\mathrm{Si}-\mathrm{Obr}-\mathrm{Si}$ bonds.

Two different strategies may be considered to develop stochastic models: the former considers that the release of a cation results from the sequential cleavage of each bond which connects it to the surface, and the latter considers that the cation release results from the

231 simultaneous cleavage of all these bonds at a given iteration step. The difference between the 232 two methods stands in the number of information required to run a simulation (for a single 233 enstatite cell, 160 bonds need to be considered following the first strategy whereas only 32 234 atoms (16 Mg and $16 \mathrm{Si}$ atoms; $\mathrm{O}$ atoms being considered as "bridges") are required for the 235 second strategy). For this reason, the second strategy is generally used and has previously 236 proven successful ${ }^{9}, 22,41,44,53$. Accordingly, our simulations were run using the following 237 probability for the release of $\mathrm{Mg}$ and $\mathrm{Si}$ atoms:

$$
P_{M}=e^{\frac{-n \Delta E_{M-O-M g}}{k_{B} T}} e^{\frac{-m \Delta E_{M-O-S i}}{k_{B} T}}
$$


where $\mathrm{M}=\mathrm{Mg}$ or $\mathrm{Si}$ and $n$ and $m$ correspond to the number of $\mathrm{Mg}$ and $\mathrm{Si}$ atoms linked to the considered $\mathrm{M}$ atom, respectively. This equation, together with knowledge of the connectivity

240 of each atom, represents the core description of the physical basis adopted for our stochastic 241 simulations. Importantly, more sophisticated relations may be found in the literature, which 242 attempt to account for various physical processes such as lattice resistance ${ }^{34,45}$, steric 243 constraints $^{9}$ or backward attachment reactions possibly resulting in self-healing of disrupted $244 \mathrm{Si}-\mathrm{O}$ br-Si bonds ${ }^{34,40-41,44}$. Importantly, even if the resulting stochastic models are physically more robust, they also introduce significant degrees of freedom in the parametrization of the resulting bond-breaking probabilities (see bond-breaking probability expressions and 247 parametrization derived in, e.g., ${ }^{9,40}$ ). In contrast, the present work was intended to assess the 248 extent to which a stochastic approach with the simplest physical basis can satisfactorily 249 account for the main face-specific features of enstatite dissolution, explaining why we used 250 the simple relations provided by Eq. (4).

Various algorithms may be used to run stochastic simulations. In the present study, we followed a strategy close to the "random select and test" approach previously described and 253 used in e.g. ${ }^{40,43}$ (see section 2.3.4). As described in these studies, this approach consists in 254 scaling to unity the most probable event, and scaling accordingly the probabilities of all other 255 events. Equation (4) then simply becomes:

$$
P_{M}=P_{M-O-M g}^{n} \times P_{M-O-S i}^{m}
$$

256 with $0<P_{M-O-M g}, P_{M-O-S i}<1$. According to ab initio and experimental studies, the most 257 probable event is the detachment of an $\mathrm{Mg}$ atom bonded to the surface via a single $\mathrm{Mg}-\mathrm{O}-\mathrm{Mg}$ 258 bond. The corresponding probability was then set to 0.99 and can be associated, by 259 identification, to the Mg-O-Mg activation energy term in Eq. (4). The two other elementary 260 probabilities $\left(P_{M g-O-S i}\right.$ and $\left.P_{S i-O-S i}\right)$ were calculated in order to observe the theoretical 261 difference of activation energies between the hydrolysis of $\mathrm{Mg}-\mathrm{O}-\mathrm{Mg}$ and that of $\mathrm{Mg}-\mathrm{O}-\mathrm{Si}$ or 
262 Si-O-Si, respectively. Considering the $a b$ initio data from ${ }^{36,38}$ for the activation energy of Si-

O-Si $\left(\Delta E_{S i-O-S i}=69 \mathrm{~kJ} / \mathrm{mol}\right)$ and Mg-O-Si $\left(\Delta E_{M g-O-S i}=59 \mathrm{~kJ} / \mathrm{mol}\right)$ hydrolyses and the

264

265 experimental data from ${ }^{55}$ for $\mathrm{Mg}-\mathrm{O}-\mathrm{Mg}$ hydrolysis $\left(\Delta E_{M g-O-M g}=60 \pm 12 \mathrm{~kJ} / \mathrm{mol}\right)$, the range of difference in activation energy that was explored is $[0 ; 10 \mathrm{~kJ} / \mathrm{mol}]$ for the $\{\mathrm{Si}-\mathrm{O}-\mathrm{Si}$; $\mathrm{Mg}-\mathrm{O}-\mathrm{Si}\}$ pair and $[0 ; 4 \mathrm{~kJ} / \mathrm{mol}]$ for the $\{\mathrm{Mg}-\mathrm{O}-\mathrm{Mg}$; $\mathrm{Mg}-\mathrm{O}-\mathrm{Si}\}$ pair.

\subsubsection{Dislocations}

Etch pits are known to nucleate at dislocations outcropping at crystal surfaces ${ }^{56}$. In order to compare the observed and simulated morphology of etch pits on each face, screw dislocations were introduced in the model. The main dislocations for enstatite follow the [001], [010] and [100] axes ${ }^{57}$. Therefore, screw dislocations are perpendicular to the different studied orientations, except for the (210) face. In order to propagate the dislocation in the volume, the distances between the first atom (located at the center of the reactive surface) and its neighbors in the $\mathrm{xOy}$ plan are calculated. The shortest distance defines the atom that will be the next one belonging to the dislocation line. The same process is repeated until reaching the opposite face of the simulated crystal. For the (210) face, a rotation of the volume is made before applying these steps in order to respect the dislocation directions ([100] and [010]). Finally, when all the atoms that belong to the dislocation line are identified, their bondbreaking probabilities are set to $1^{9,22}$.

\subsubsection{Dissolution algorithm}

The "random select and test" $\left(\mathrm{RST}^{40,43}\right)$ and "divide and conquer" approaches $\left(\mathrm{DaC}^{43}\right.$,

${ }^{58}$ ) are two different algorithms commonly used in stochastic simulations. Nowadays, the DaC algorithm is usually preferred because it requires less computer time. Furthermore, it provides a correspondence between iteration and time ${ }^{9}$. However, $\mathrm{DaC}$ algorithms cannot reproduce 
287 simultaneous events, and favor a "layer-by-layer" removal of atoms ${ }^{41}$. For these reasons, we 288 preferred using an approach close to the "primitive" RST despite its poor computation 289 efficiency. Moreover, time cannot be associated a priori to a number of iterations. This 290 relation has to be inferred using at least two experimental data sets (e.g., two dissolution rates 291 for two different faces). By measuring mean dissolution rates for 4 different faces, we made 292 sure that the problem was overconstrained, ensuring a well-established relationship between 293 time and simulation steps (iterations). The crystal is described by the coordinates of the $\mathrm{Mg}$ and $\mathrm{Si}$ atoms and the connectivity of each atom to its neighbors follows the rules described in Section 2.3.1. Only the cations that have an incomplete first coordination sphere (incomplete connectivity), are considered to be located at the crystal surface, and may experience dissolution. For each $\mathrm{Mg}$ and $\mathrm{Si}$ atom, an integer number indicates the three possible states of the atom: (i) dissolved, (ii) at the crystal surface, or (iii) inside the crystal. This indicator allows counting the number of dissolved cations and their nature $(\mathrm{Mg}$ or $\mathrm{Si})$ and identifying the atoms located at the surface in an efficient way.

The algorithm for simulating the dissolution process is as follows: 1. At each iteration step $k$, all cations of the simulated crystal volume are scanned sequentially (Loop 1 in Fig. S2).

2. For each surface cation, a random number $Z$ uniformly distributed between 0 and 1 is generated. The probability of dissolution of that atom $P_{M}$ is computed as the product of the bond-breaking probabilities of the bonds that link it to the crystal following Eq. (5). If $Z<P_{M}$, the atom is released (dissolved). If not, the scan of the atoms is moving on (Loop 2 in Fig. S2).

3. When the scan of all atoms is completed, the first coordination spheres of the remaining atoms are updated if necessary (i.e., when a removed atom was 
belonging to the coordination spheres of one of the remaining atoms; cf. Loop 3 in Fig. S2). Because the coordination spheres are modified, the probability of dissolution $P_{M}$ of the corresponding atoms are increased.

4. The number of released $\mathrm{Si}$ and $\mathrm{Mg}$ atoms at iteration $k$ is saved for postprocessing.

5. The iteration number is incremented and the process continues step 1 .

\subsubsection{Model outputs}

The outputs of the simulations were used to document face-specific features of enstatite dissolution, such as (i) the mean dissolution rates at steady-state conditions, (ii) the thickness of the Si-rich surface layer that may result from preferential leaching of $\mathrm{Mg}$ (if any) and (iii) the etch pit morphology.

The dissolution rates may be calculated following two different approaches. First, the

324 list of surface cations after a given iteration is used to calculate the corresponding mean 325 elevation of the surface $\left(z_{\text {surface }}=\sum_{i=1}^{N_{\text {atome,surface }}} Z_{i} / N_{\text {atom,surface }}\right)$ and infer the 326 corresponding mean surface retreat rate ([nm/iteration $]$ ), which can be converted into a 327 surface normalized dissolution rate $r_{\bmod , t o p o}^{(h k l)}\left(\left[\mathrm{mol} / \mathrm{m}^{2} / \mathrm{iter}\right]\right)$ using Eq. (1) (in which the 328 number of iterations is substituted for time). When steady-state conditions are reached (i.e., 329 when $r_{\text {mod,topo }}^{(h k l)}$ becomes constant), this approach can be related to the dissolution rates 330 estimated using VSI (see section 2.2). Of note, the difference in terms of surface areas 331 between the simulated $\left(0.33 \mu \mathrm{m}^{2}\right.$ for the largest) and measured (dozens of $\left.\mathrm{mm}^{2}\right)$ surfaces 332 preclude any direct use of the rate spectra concept ${ }^{15}$, so that in the present study, only the 333 mean surface retreat rates were subsequently used as a criterion to assess the correspondence 334 between simulated and measured dissolution rates. 
A second approach considers the amount of $\mathrm{Mg}$ and $\mathrm{Si}$ atoms released at each iteration, as could be determined experimentally using ICP-AES solution analyses. Distinct rates based on $\mathrm{Mg}\left(r_{\bmod , M g}^{(h k l)}\left(\left[\mathrm{mol} / \mathrm{m}^{2} /\right.\right.\right.$ iter $\left.\left.]\right)\right)$ and $\mathrm{Si}\left(r_{m o d, S i}^{(h k l)}\left(\left[\mathrm{mol} / \mathrm{m}^{2} /\right.\right.\right.$ iter $\left.\left.]\right)\right)$ release were calculated following:

$$
\begin{aligned}
r_{\text {mod,Mg }}^{(h k l)} & =\frac{\sum_{i=1}^{i t} N_{M g, i} * V_{\text {cell }}}{i t * N_{M g, c e l l} * S * \bar{V}} \\
r_{\text {mod,Si }}^{(h k l)} & =\frac{\sum_{i=1}^{i t} N_{S i, i} * V_{\text {cell }}}{i t * N_{S i, c e l l} * S * \bar{V}}
\end{aligned}
$$

339 where it represents the iteration step at which the calculation is performed, $N_{M, i}$, the number of

$340 \mathrm{Mg}$ or Si atoms released after the $i^{\text {th }}$ iteration, $N_{M, \text { cell, }}$, the number of $\mathrm{Mg}$ or $\mathrm{Si}$ atoms in the cell 341 (16), $V_{\text {cell }}$ the enstatite cell volume, $\bar{V}$ the molar volume of enstatite and $S$, the geometric 342 surface area of the reactive surface.

343 While this approach eventually yielded results very close to the previous method, it

344 further provided information regarding the stoichiometry of the dissolution by comparing the 345 evolution of the departure of the $\mathrm{Mg}$ and $\mathrm{Si}$ atoms, and eventually, regarding the existence 346 and thickness of a Si-rich surface layer, which was previously documented for inosilicates 347 weathered experimentally ${ }^{18,23,59-61}$. Since the model does not consider the backward reaction 348 of Si attachment to the surface (see discussion in ${ }^{41,62}$ ), it only indicates a lower bound for the 349 thickness of the layer resulting from cation depletion, ignoring possible Si re-deposition 350 following an interfacial dissolution-reprecipitation mechanism.

351 Finally, for simulations run with dislocations, the resulting etch pits and surface 352 retreats were calculated using SurferC. The coordinates of the atoms at the surface were 353 stored and used as an input file for Surfer. The minimum curvature method was used to 354 calculate the mean surface retreat at a given iteration. 

instead of elapsed time. However, in order to compare modeled and measured dissolution rates, it is necessary to link a single iteration to a physical time increment. The correspondence between time and iteration was determined following Eq. (7):

$$
t=\left\langle\frac{r_{m o d}^{(h k l)}}{r_{\text {exp }}^{(h k l)}}\right\rangle i t
$$

\section{Results}

\subsection{Face-specific dissolution rates of enstatite revealed experimentally}

Fig. 2A shows the temporal evolution of the mean surface retreat measured using VSI.

Whereas the $(h k 0)$ faces were reacted for durations of up to three weeks, the rapid increase of the roughness of the (001) face prevented the measurements of surface topography for durations exceeding a couple of days. The main results are as follows:

(i) the dissolution rate is constant through time (at least from the first experimental measurements) for all of the four faces, within experimental uncertainties;

(ii) the dissolution rates of the samples left in the reactor all over the duration of the experiments are similar to those that were periodically retrieved from the reactors;

(iii) enstatite dissolution is an anisotropic process (i.e., the slopes of the linear regressions differ from one face to the other). The face-specific dissolution rates $\left(r_{\text {exp }}^{(h k l)}\right)$ observe the following trend: $r_{\text {exp }}^{(001)} \gg r_{\text {exp }}^{(210)}>r_{\text {exp }}^{(010)} \geq r_{\text {exp }}^{(100)}$. The mean values of dissolution rates are $71.8 \pm 13.9,8.5 \pm 1.5,3.0 \pm 1.0$ and $2.6 \pm 0.6 \mathrm{nmol} / \mathrm{m}^{2} / \mathrm{s}$ for the $(001)$ (210), (010) and (100) faces, respectively (Fig. 2B). 

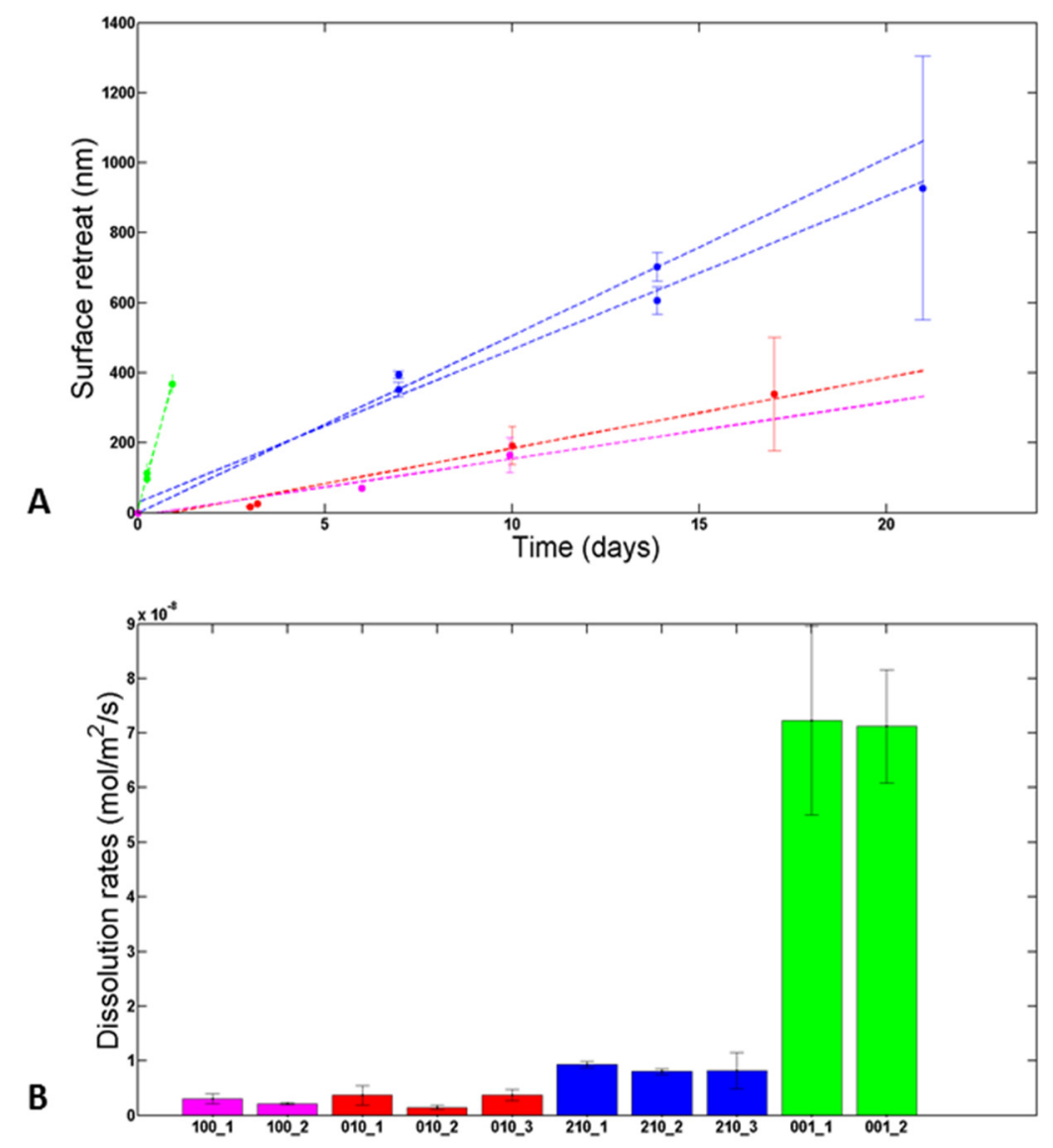

378 Fig. 2. A. Face-specific temporal evolution of the mean surface retreat measured with VSI and associated linear

379 regressions. B. Measured face-specific dissolution rates. For both graphs, magenta, red, green and blue colors 380 stand for the results obtained for (100), (010), (001) and (210) faces, respectively.

The etch pits possibly formed on each surface were too small to be properly 384 investigated by VSI, whose resolution is close to $300 \mathrm{~nm}$ at the maximum 100x385 magnification. Apart from the surface retreat between the masked and unmasked portions of 386 the samples (Fig. 3), no specific topography feature could be evidenced using VSI. 

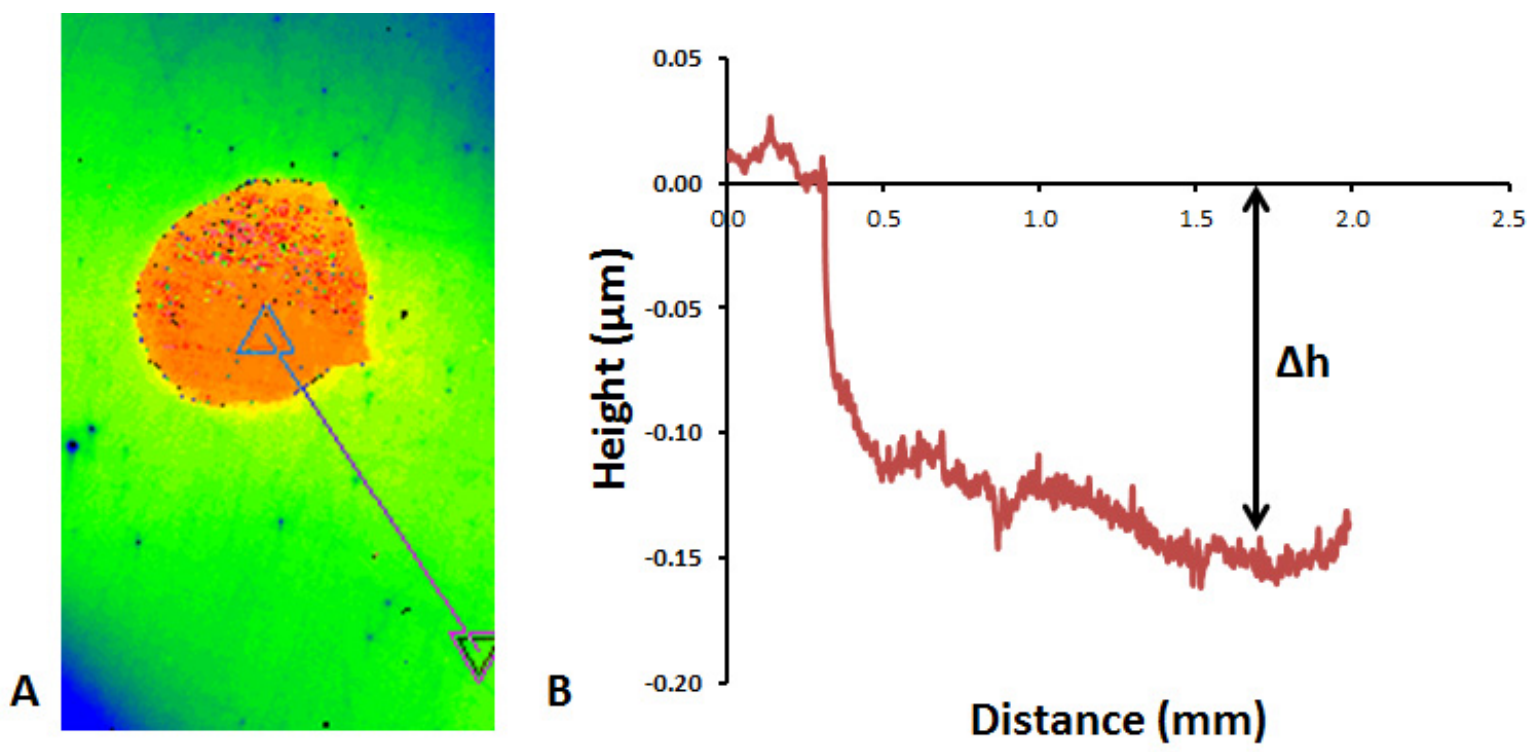

Fig. 3. A. Surface topography of the (001) surface dissolved for $\sim 8$ h measured using VSI. The red spot represents the mask (non-reacted) area while the blue/green area represents the reacted surface. B. Topography of the surface (straight line in A) after dissolution. The upper part corresponds to mask area while the lower part corresponds to the reacted area.

SEM imaging of the reacted surfaces revealed that etch pits did nucleate on three of the four investigated faces (Fig. 4), and confirmed that their lateral extension was too modest to be imaged by VSI. The (100) and (010) faces exhibited similar lenticular pits elongated following the $c$-axis (the major axis is more than 6 times larger than the minor axis). The shape of the pits projected to the horizontal surface shows a central symmetry, consistent with 398 the shape previously described in the literature for pyroxenes in general ${ }^{18,60,63-65}$. Two types 399 of pits are visible on the (210) face: while the former is similar to the ones observed on the 400 (100) and (010) faces (with a small minor axis compare to the major axis), the latter, also 401 elongated following the c-axis, presents a wider minor axis (3 times smaller than the major 402 axis). In addition to this difference of minor-axis length, these pits differ from the ones 403 observed on the other faces by their non-symmetrical, half-moon shape. Whereas the lowest 404 points for the pits developed on the (100) and (010) faces are located at the center of the pits, 
conversely, for pits developed on the (210) face, the lowest point is located at the center of the major-axis but shifted on one edge of the minor-axis (Fig. 4C). by SEM on surface areas of $\sim 300 \mu \mathrm{m}^{2}$. Of note, polishing scratches also represented an 410 important source of etch pits. Because they can contribute to the global dissolution rate by 411 exposing step sites, they have been taken into account in the calculation of the dislocation 412 density.
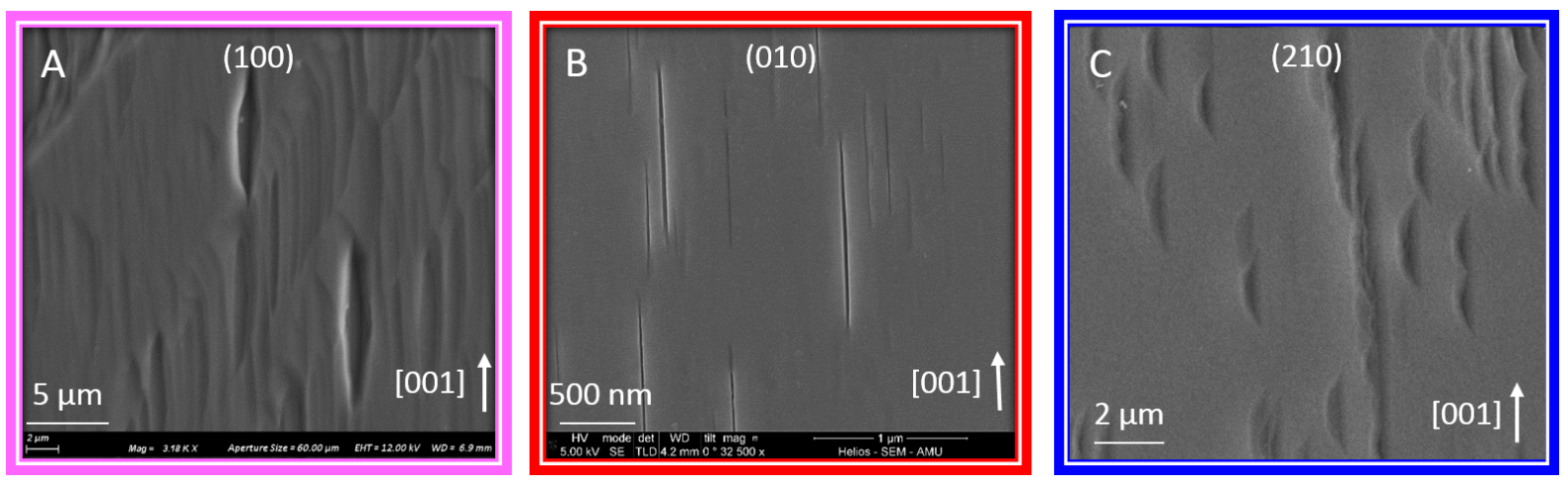

414 Fig. 4. SEM images of the surface of (001) (A), (010) (B) and (210) faces reacted at pH 0 for 7 to 21 days. The

415 images reveal the nucleation of lenticular etch pits elongated following the [001] direction. Note the asymmetric shape of the pits nucleated on the (210) face, as opposed to those developed on the other two faces.

The dislocation density on the (100) and (210) faces was found to be similar (on the order of $4.9 \pm 0.3 \times 10^{8}$ dislocations $\left./ \mathrm{cm}^{2}\right)$, and is about two orders of magnitude greater than that measured on the $(010)$ face $\left(9.8 \times 10^{6}\right.$ dislocation $\left./ \mathrm{cm}^{2}\right)$. The dislocation density on the 421 (001) face could not be determined because of the rapid roughening of the surface, which 422 impeded the identification of individual etch pits. These dislocation densities are in agreement 423 with other studies ${ }^{66-67}$, which reported dislocation densities ranging between $4.0 \times 10^{7}$ and 7.0 $424 \times 10^{8}$ dislocations $/ \mathrm{cm}^{2}$. The close correspondence between the dislocation density calculated 425 for the (100) and the (210) faces may be explained by the main orientation of screw 
dislocations for the enstatite structure. As mentioned in section 2.3.3, the main dislocations in enstatite follow the [100], [010] and [001] directions ${ }^{57}$. Therefore, outcropping dislocations at the (210) surface should represent the sum of the dislocation outcropping at the (100) and the (010) surfaces, which is consistent with our observations.

TEM investigations performed on FIB thin sections prepared on the reacted samples

431 revealed the occurrence of amorphous surface layers on (010), (210) and (001) samples, with

432 a thickness specific to the surface orientations (Fig. 5). The thickest layers were evidenced on 433 (001) samples (15-20 nm; cf. Figs. 5C-D). The layers developed on (210) and (010) samples 434 have similar thickness $(\leq 4 \mathrm{~nm}$; cf. Fig. 5B), whereas no surface layer could be clearly 435 evidenced on (100) samples (Fig. 5A). The layers developed on (001) samples were thick 436 enough to analyze their chemical composition with STEM-EDX, which revealed that they are 437 Si-rich and Mg-depleted (Fig. 5D). The similarity of these results with those reported by 438 Daval et al. ${ }^{18}$ for diopside dissolved at $\mathrm{pH} 1$ is noteworthy. Finally, it was possible to 439 determine the cross-section morphology of etch pits nucleated on the (100) and (010) faces, as 440 the FIB thin sections were realized in locations where etch pits were particularly abundant. 441 Regarding the (010) face, TEM images revealed that the pit geometry observes an axial 442 symmetry with respect to the [010] axis, and that the pit walls are particularly steep, forming 443 an angle of $93^{\circ} \pm 2^{\circ}$ with the (010) surface (Fig. 5B). Similarly, the walls of the pits 444 developed on the (100) face formed an angle of $97^{\circ} \pm 5^{\circ}$ with the (100) surface, although the 445 pits appear to be flat-bottomed (Fig. 5A). Overall, these results confirmed that profilometry 446 techniques such as atomic force microscopy or vertical scanning interferometry would have 447 failed to reveal the 3D-geometry of such etch pits. 

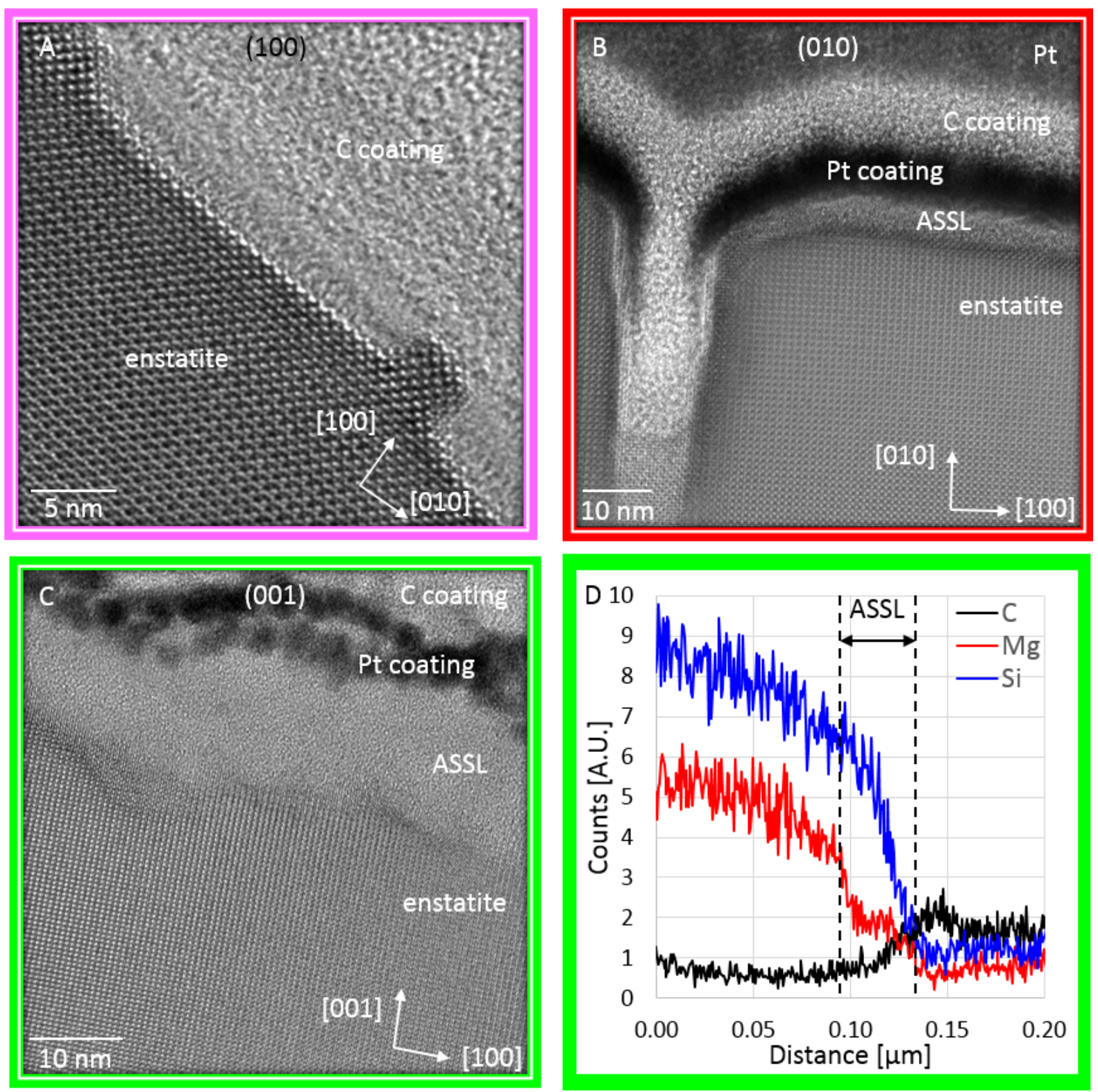

450 Fig. 5. TEM characterizations of FIB thin sections prepared on (100) (A), (010) (B), and (001) (C and D) reacted surfaces. HRTEM images in (B) and (C) reveal the formation of a nm-thick amorphous layer formed on the surface, with a sharp crystallographic boundary between enstatite and the surface layer. For the FIB thin section realized on (001) surface, STEM-EDX profiles measured parallel to the [001] direction reveal that the surface layer is Si-rich and Mg-depleted (D). 

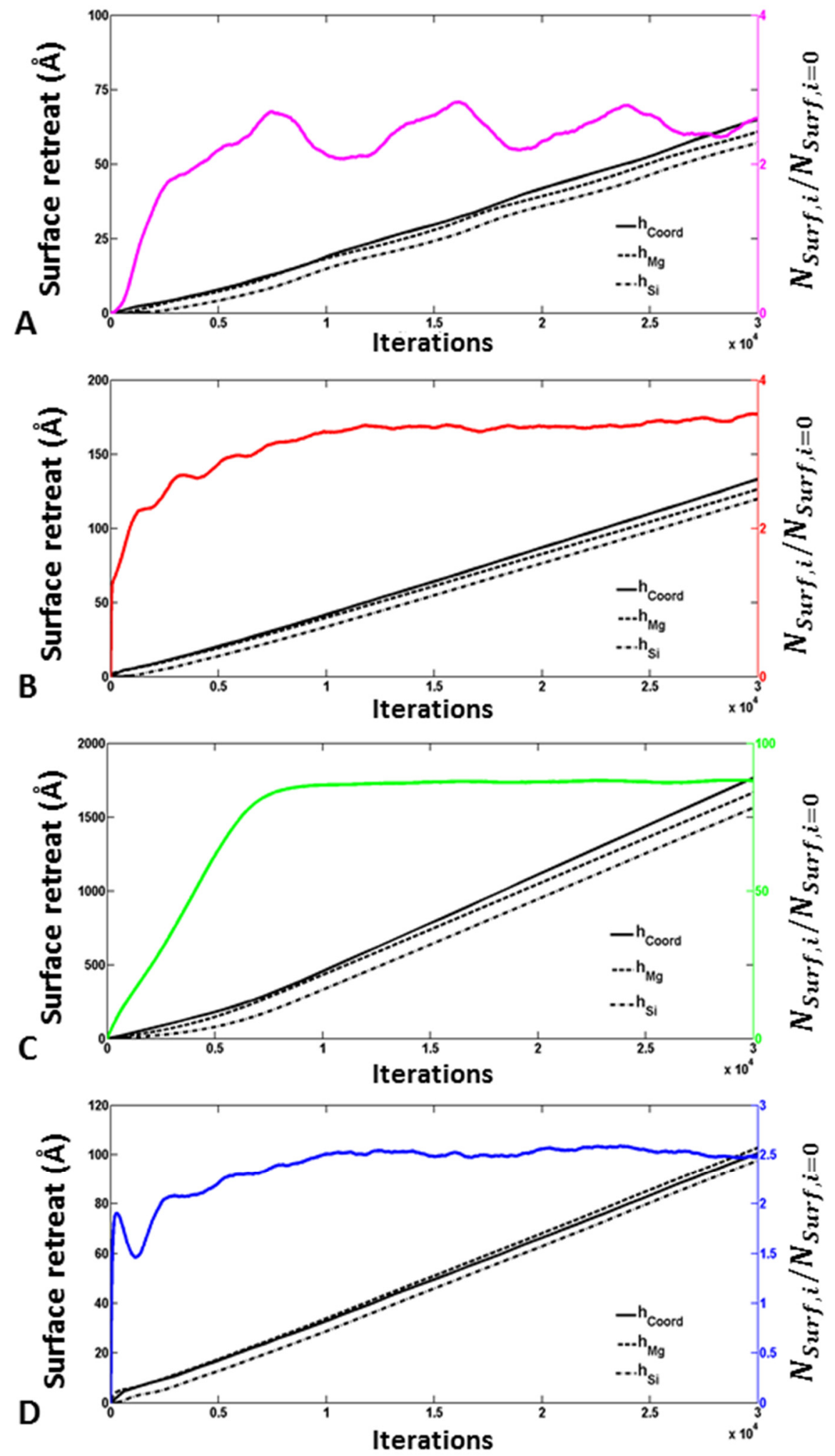

459 Fig. 6. Outputs of the simulations conducted with the bond-breaking probabilities corresponding to the best

460 agreement between measured and modeled dissolution rates (see text for details) for (100) (A), (010) (B), (001)

461 (C) and (210) (D) faces. The evolution of the modeled surface retreat calculated following three different

462 methods (see text) is depicted with black lines. The color lines stand for the evolution of the number of surface 
487 for each face, the modeled face-specific dissolution rates $r_{\bmod }^{(h k l)}$ observe the following trend: cations, normalized to the initial number of cations at the enstatite surface. Note that the increase of the number of surface atoms is much greater for $(001)$ face (about an 80 -fold factor) than for the other $(h k 0)$ faces (between a 2.5- and 3.8-fold factor).

breaking probabilities that have been tested, is the attainment of a steady-state dissolution regime, which is characterized by a congruent release of $\mathrm{Mg}$ and $\mathrm{Si}$ cations and a constant dissolution rate (Fig. 6). This steady-state regime was found to result from the attainment of a constant number of atoms at the surface of each face, as illustrated in Fig. 6 (color lines).

During the initial transient period, $\mathrm{Mg}$ is released preferentially, and enstatite dissolution rate based on Si release increases gradually. The duration and the shape of the transient period depend on the set of bond-breaking probabilities that are used to run the simulations and is a function of surface orientation. In a general manner, the steady-state regime is achieved earlier for the $(h k 0)$ faces than for the $(001)$ face, for which the initial non-congruence of the dissolution is also more pronounced (Fig. 6). As a consequence, thicker ASSLs are expected to build up on the (001) face, compared to the $(h k 0)$ faces. When one considers the set of bond-breaking probabilities that allows for the best agreement between the modeled and measured steady-state face-specific dissolution rates (see below), the modeled thickness of ASSL is on the order of 1-2 atomic monolayers for all $(h k 0)$ faces, as opposed to $\sim 10 \mathrm{~nm}$ for the ASSL developed on the (001) face.

The modeled absolute values of steady-state dissolution rates and the relative differences between the reactivity of the four faces depend on the set of bond-breaking probabilities that were used to conduct the simulations. Considering a range of probabilities that is consistent with the literature (see section 2.3.2) and the dislocation density determined experimentally

$488 r_{\text {mod }}^{(001)} \gg r_{\text {mod }}^{(h k 0)}$. The relative differences between the modeled dissolution rates for the 
various $(h k 0)$ faces depend on the set of probabilities used to run the simulations. The best

490 agreement between modeled and measured steady-state dissolution rates is obtained for $P_{M g-O}$

$M g=0.99 ; P_{M g-O-S i}=0.4$ and $P_{S i-O-S i}=0.0146$ (i.e., $\Delta E_{S i-O-S i}-\Delta E_{S i-O-M g}=10 \mathrm{~kJ} / \mathrm{mol}$

and $\left.\Delta E_{M g-O-M g}-\Delta E_{S i-O-M g}=2.7 \mathrm{~kJ} / \mathrm{mol}\right)$, for which the modeled face-specific

493 propagation (and thus, difficult pit opening), as suggested by the shape of their bottom along

512 the $c$-axis. The bottom of the pits developed on the (100) face are surrounded by steep pit 513 walls $\left(\theta \approx 93^{\circ} \pm 1^{\circ}\right.$ between the surface and pit walls $)$. 
515 (elongated following the $c$-axis, and symmetric with respect to the $a$ - and $c$-axes, with similar 516 length and width $(\approx 5-10 \mathrm{~nm})$ after 2,000 iterations $)$, although the pits are deeper $(\approx 20 \mathrm{~nm}$ 517 against $\approx 10-15 \mathrm{~nm}$ after 2,000 iterations) and thinner than those developed on the (100) face. 518 Of note, their growth rate is lower than that of pits developed on the (100) face. The bottom of 519 the pits developed on the (010) face is surrounded by steep pit walls $\left(\theta \approx 95^{\circ}\right.$ between the 520 surface and pit walls). developed on (100) and (010) faces. However, their lenticular shape is not as well defined and approaches that of a half-moon: indeed, one edge of the pit subparallel to the $c$-axis is straighter than the other, which is more curvilinear. In addition, whereas the deepest point of pits modeled on (100) and (010) faces is located at the center of the pit, the pits developed on the (210) face are asymmetric (see cross- section 7) and the deepest point (3-4 nm) is located at the center of the pit following the $c$-axis, but shifted on one edge of the minor-axis $([-210])$. Finally, although no etch pit could be evidenced experimentally on (001) faces, the model predicts that small $(\approx 10 \mathrm{~nm})$ and deep $(>40 \mathrm{~nm})$ subcircular etch pits may grow on the 530 (001) face if screw dislocations parallel to the $c$-axis are implemented. However, unlike the 531 other faces, etch pits developed on the (001) face reach a stable radius or tend to vanish, as a result of the increasing roughness of the surrounding surface, possibly explaining why such etch pits remained out of reach of our analytical characterizations. 

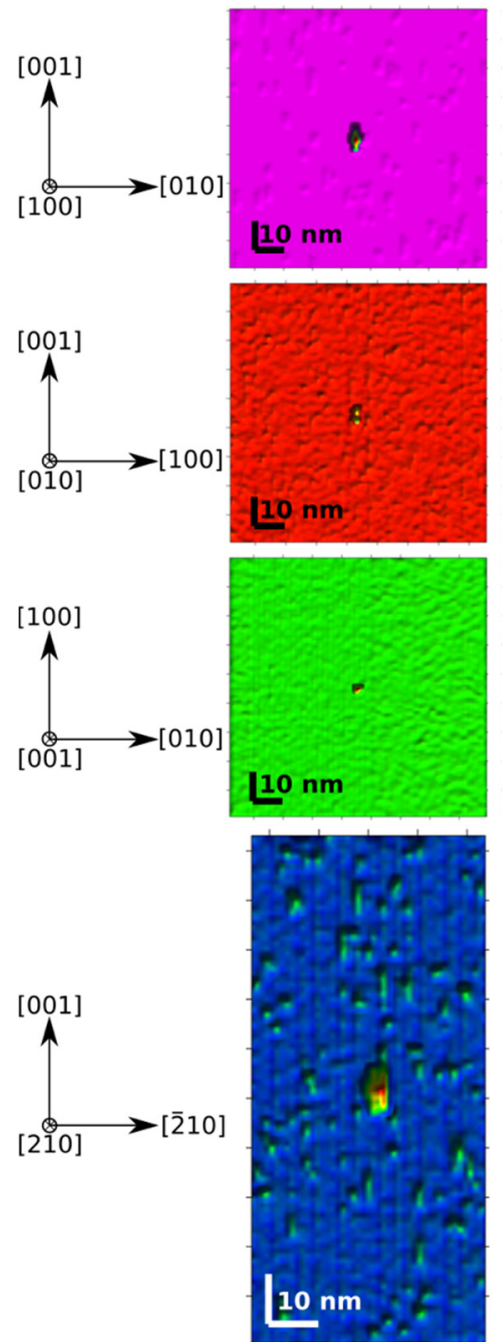

534

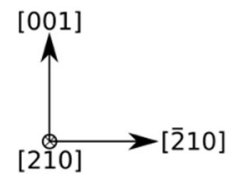

\section{Discussion}

and $71.8 \mathrm{nmol} / \mathrm{m}^{2} / \mathrm{s}$ at $\mathrm{pH} 0$ and $T=90{ }^{\circ} \mathrm{C}$. These values are between one and two orders of

544 magnitude lower than expected using the dissolution rate law derived from powder
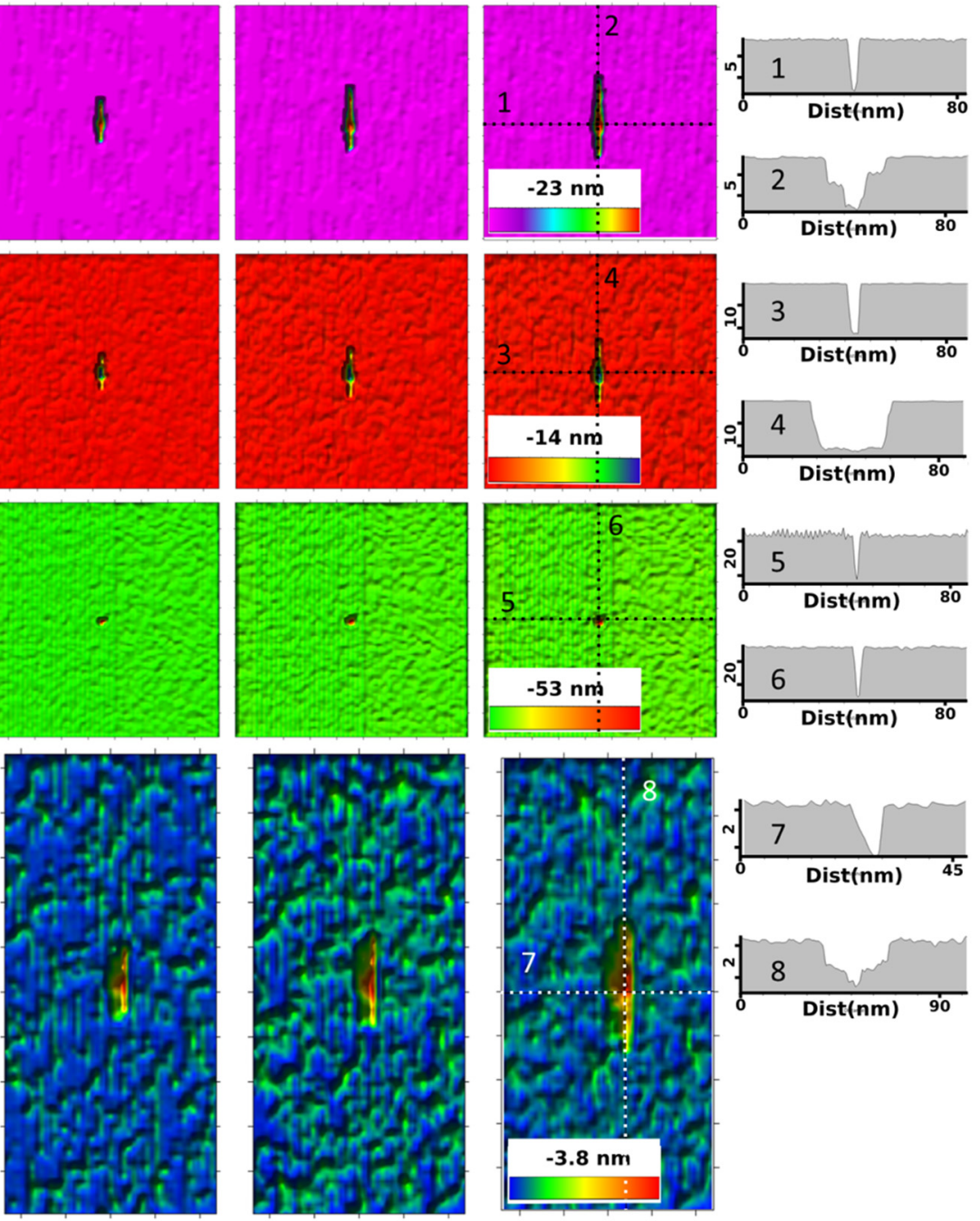

\subsection{Factors influencing the face-specific dissolution rates of enstatite and comparison} with previous studies

As reported above, the face-specific dissolution rates of enstatite range between 2.6 
545 dissolution experiments conducted by Oelkers ${ }^{68}$ (between 730 and $973 \mathrm{nmol} / \mathrm{m}^{2} / \mathrm{s}$ ), which 546 represents the largest enstatite dissolution kinetics dataset that we are aware of. Such 547 discrepancies may either be ascribed to the contribution of edges and corners, whose 548 reactivity is much greater than that of faces ${ }^{13,46}$ and which are overrepresented when using 549 powders. It may also be due to the very low $\mathrm{pH}$ investigated in the present study, which may 550 result in a saturation of proton surface sites ${ }^{69}$, possibly leading to a weaker $\mathrm{pH}$-dependence of 551 silicate dissolution rate than expected in the extreme acidic $\mathrm{pH}$ domain. In any case, the 552 present study illustrates the unsuitability of isotropic dissolution rate laws derived from 553 powder dissolution experiments to predict the amplitude and absolute values of face-specific 554 dissolution rates, as pointed out in previous studies ${ }^{15,21,70}$.

555 The results show that the dissolution rate of the (001) face is about one order of 556 magnitude greater than that of the other investigated $(h k 0)$ faces. Among these latter faces, the 557 dissolution rates of the (100) and (010) faces are similar within uncertainties, and are about 558 three times slower than that of the (210) face. If one considers the crystallographic similarities 559 existing between the (110) face of diopside and the (210) face of enstatite (both faces 560 correspond to the cleavage plane of these minerals, and intersect the highest density of Mg-O561 Si bonds), these results are in excellent agreement with those obtained on diopside $562\left(\mathrm{Ca}_{0.5} \mathrm{Mg}_{0.5} \mathrm{SiO}_{3}\right)^{18}$, which also belongs to the pyroxene group (Fig. 8B). Note however that 563 the anisotropic reactivity of enstatite seems to be less pronounced than that of diopside. This 564 is likely due to the presence of $\mathrm{Ca}$ ions in the diopside structure, which offers more 565 combinations for the bond-breaking probabilities (and therefore, detachment rates) of $\mathrm{Mg}$ and $566 \mathrm{Si}$ atoms. Indeed, the hydrolysis rates of $\mathrm{Ca}-\mathrm{O}-\mathrm{Si}$ and $\mathrm{Ca}-\mathrm{O}-\mathrm{Ca}$ bonds are faster than that of $567 \mathrm{Mg}-\mathrm{O}-\mathrm{Si}$ and $\mathrm{Mg}-\mathrm{O}-\mathrm{Mg}$ bonds, as demonstrated experimentally ${ }^{71}$ and indirectly confirmed 568 theoretically following ab initio calculations ${ }^{38}$. 

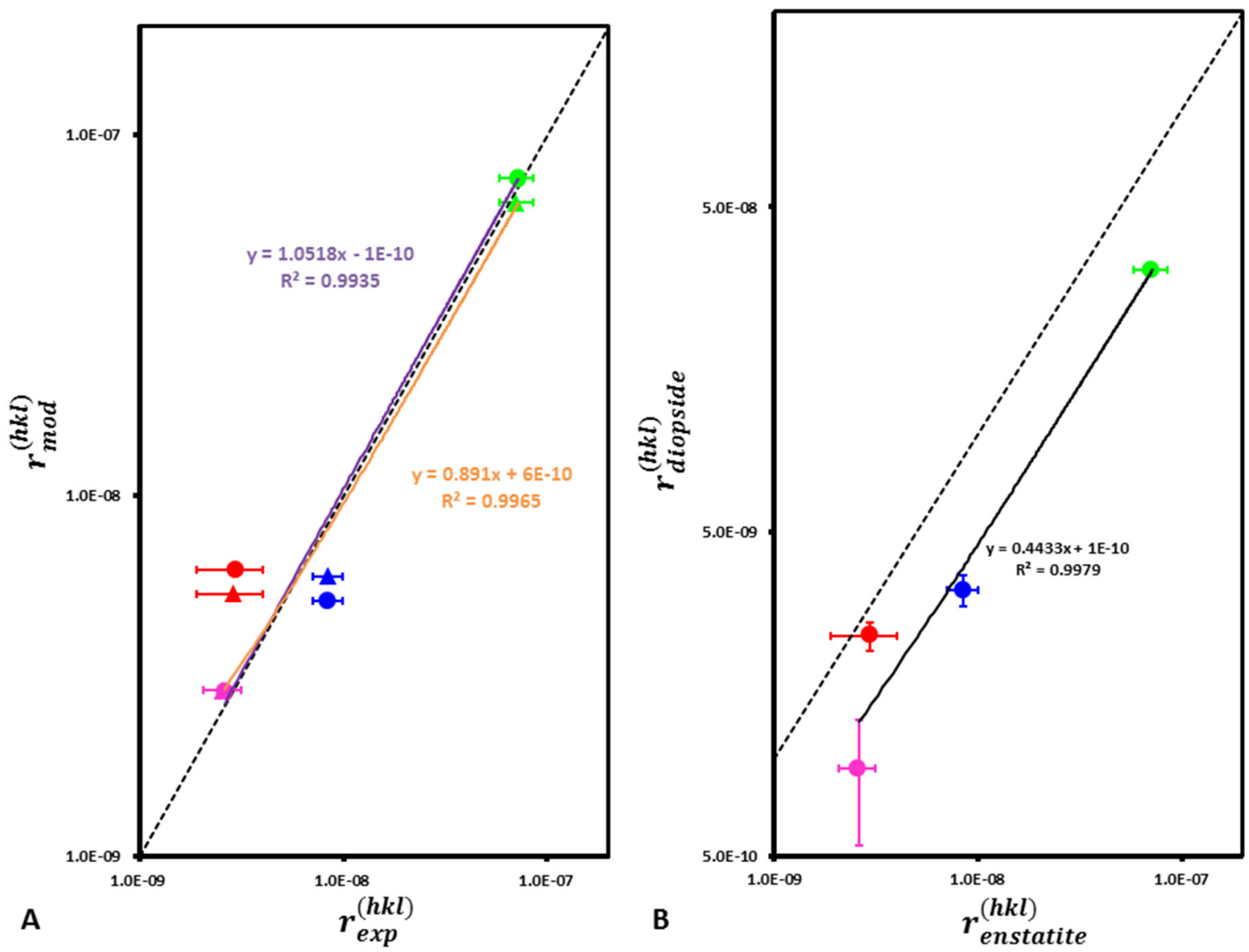

570 Fig. 8. A. Best agreement between modeled and measured face-specific enstatite dissolution rates. The triangles

571 and circles stand for simulations conducted with and without dislocations, respectively. Note that the modeled

572 dissolution rate of the (001) face is also affected because the time for one iteration changes as a function of the

573 mean ratio between experimental and modeled dissolution rates (Eq. 7). B. Comparison between enstatite and

574 diopside ${ }^{18}$ face-specific dissolution rates. For both graphs, magenta, red, green and blue colors stand for the 575 results obtained for (100), (010), (001) and (210) faces, respectively.

The factors that are most frequently invoked to account for the anisotropy of silicate

578 dissolution include (i) the crystallographic bonding structure and in particular, the

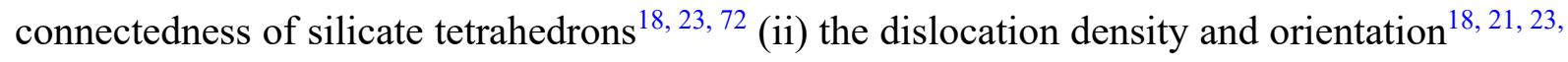
73-74 and (iii) the formation of ASSLs, whose transport properties may differ as a function of

581 the crystallographic orientation ${ }^{18,20,23}$. 
Considering the conditions that are thought be required for the development of 583 passivating ASSLs (i.e., oxic conditions and mildly acidic $\mathrm{pHs}$, see ${ }^{20,23,75-76}$ ), the latter factor 584 (iii) can be safely ruled out in the present study. reactivity may benefit from the comparison between the outputs of the simulations and the experimental results. When the simulations are run without implementing any dislocation in the enstatite structure, the reactivity of the (001) face is strikingly greater than that of the other ( $h k 0)$ faces, as observed experimentally (Fig. 6). Therefore, this suggests that the connectedness of silicate tetrahedrons dictates the anisotropic reactivity of enstatite at first order: as previously pointed out by Daval et al. ${ }^{18}$, the release of Si atoms from the (001) face to the solution requires the cleavage of one $\mathrm{Si}-\mathrm{O}-\mathrm{Si}$ bond only, while it would require the (less 593 likely) simultaneous cleavage of two $\mathrm{Si}-\mathrm{O}-\mathrm{Si}$ bonds on the $(h k 0)$ faces, which are parallel to 594 the silicate tetrahedron chains.

The connectedness of $\mathrm{SiO}_{4}$ tetrahedrons cannot be invoked to distinguish between the 596 reactivity of the three other investigated $(h k 0)$ faces, because it is the same for all of them. 597 However, because the outputs of the simulations show that the dissolution rates of these three 598 faces are different even without implementing any dislocation, this suggests that the 599 crystallographic bonding structure also exerts a strong control on the face-specific reactivity.

600 As it can be seen in Fig. 1, the $\mathrm{Mg}$ and $\mathrm{Si}$ atoms are organized following planes that are 601 parallel to the (100) face. If one supposes that the detachment rate of Si atoms connected to 602 two other $\mathrm{Si}$ atoms is lower than that of $\mathrm{Mg}$ atoms (in agreement with the respective 603 activation energies for the hydrolysis of $\mathrm{Si}-\mathrm{O}-\mathrm{Si}, \mathrm{Si}-\mathrm{O}-\mathrm{Mg}$ and $\mathrm{Mg}-\mathrm{O}-\mathrm{Mg}$ bonds, see section 604 2.3.1), it can be assumed that the progression of the dissolution in the [100] direction will be 605 hampered by the sluggishness of the dissolution of these Si-rich planes. Conversely, the 606 detachment of accessible $\mathrm{Mg}$ atoms located below the first atomic plane of the (010) face may 
607 contribute to destroying the first coordination spheres of the topmost Si atoms, which eventually increase their probability of detachment. In turn, this explanation would account 609 for the fact that the slowest dissolving face is (100), and the dissolution rates inferred from the

610 simulations therefore observe the following trend: $r_{\text {mod }}^{(100)}<r_{\bmod }^{(210)}<r_{\text {mod }}^{(010)}<<r_{\text {mod }}^{(001)}$, the

611 (210) face representing an intermediate configuration between the (100) and (010) faces. Finally, these simple crystallographic considerations do not account for the 613 observation that the dissolution rate of the (210) face is greater than that of the (010) face. 614 Interestingly, running the simulations with the appropriate dislocation density measured experimentally allows to obtain a global trend for the face-specific reactivity of enstatite

616 which matches exactly to that measured experimentally, with $r_{\text {mod,exp }}^{(100)}<r_{\text {mod,exp }}^{(010)}<r_{\bmod , \exp }^{(210)}$ $617<r_{\bmod , \exp }^{(001)}$ (see details in section 4.2). These results confirm the critical contribution of 618 dislocations to mineral dissolution rates (e.g., ${ }^{9,21,74,77-78}$ ).

619 To sum up, both the crystallographic bonding structure and the presence of crystal 620 defects (and in particular, dislocations) contribute to the observed anisotropic reactivity of 621 enstatite, in agreement with previous studies dedicated to the face-specific dissolution rates of 622 minerals.

\subsection{Assessing the agreement between measured and simulated rate data}

A total of 45 sets of activation energies for the thermally activated probabilities of breaking $\mathrm{Mg}-\mathrm{O}-\mathrm{Mg}, \mathrm{Mg}-\mathrm{O}-\mathrm{Si}$ and $\mathrm{Si}-\mathrm{O}-\mathrm{Si}$ bonds were tested to cover the possible range of hydrolysis described in section 2.3.2. Three different complementary metrics were used to evaluate quantitatively the agreement between simulation outputs and experimental results: classical metrics such as the relative root mean square error $(R R M S)$ and the relative mean error $(R M E)$, and an additional original metrics $(S a I)$ based on a linear combination of the 
631 slope and the intercept of the line of best fit, i.e., the line obtained through linear regression 632 between modeled dissolution rates vs. measured dissolution rates. These metrics are defined 633 by:

$$
\begin{gathered}
R R M S=\frac{1}{N_{E}} \sqrt{\sum_{n=1}^{N_{E}}\left(\frac{r_{m o d}^{(h k l)_{n}}-r_{\text {exp }}^{(h k l)_{n}}}{r_{\text {exp }}^{(h k l)_{n}}}\right)^{2}} \\
R M E=\frac{1}{N_{E}} \sum_{n=1}^{N_{E}} \frac{r_{m o d}^{(h k l)_{n}}-r_{\text {exp }}^{(h k l)_{n}}}{r_{\text {exp }}^{(h k l)_{n}}} \\
S a I=a b s(1-a)+a b s\left(\frac{b}{<r_{\text {exp }}^{(h k l)}>}\right)
\end{gathered}
$$

634 where $r_{\text {exp }}^{(h k l)}$ (resp. $r_{\text {mod }}^{(h k l)}$ ) is the dissolution rate for face $(h k l)$ estimated experimentally (resp. 635 by the model), $N_{E}$ is the number of experimental values (4 in our case), $a$ is the slope of the 636 best fit line, $b$ is the intercept of the best fit line and $\left\langle r_{\text {exp }}^{(h k l)}\right\rangle$ the average of all 637 experimental dissolution rates.

638 The RRMS index indicates how spread out are the differences between the modelled 639 values and the observed values or how close are, in average, these differences around the line 640 of best fit. The $R M E$ index allows detecting possible bias, i.e., if RME is significantly greater 641 than 0 (resp. lower than 0), the model overestimates (resp. underestimates) the observed 642 values. The information provided by the best fit line is gathered in the $S a I$ index. Because of 643 differences in units ( $a$ is dimensionless, $b$ has the dimension of the dissolution rate), the 644 second term of $S a I$ is divided by $\left\langle r_{e x p}^{(h k l)}>\right.$. We used this reference for model performance 645 comparisons because it is a common reference for all data. RRMS-RME indices and the SaI index provide different kinds of information. Any set 647 of probabilities (or their corresponding activation energies) that minimizes the $R R M S$ and $648 R M E$ indices does not necessarily minimizes the $S a I$ index as well (e.g., the set of 
649 probabilities that minimizes the $R R M S$ and $R M E$ indices is $\left[P_{M g O M g}=0.99, P_{S i O M g}=0.3\right.$ and $\left.650 P_{S i O S i}=0.0109\right](R R M S=22 \%$ and $R M E=17 \%)$, whereas it overestimates the dissolution rate 651 anisotropy $(\mathrm{SaI}=0.52)$. On the other hand, the set that allows for the best $S a I$ is $[P$ MgOMg $=$ $6520.99, P_{S i O M g}=0.40$ and $\left.P_{S i O S i}=0.0146\right](S a I=0.06)$, corresponding to $R R M S$ and $R M E$ of $65330 \%$ and $22 \%$, respectively). In order to compare the 45 sets of probabilities, we finally 654 defined a composite metric that we called best agreement $(B A)$ for each set $i$ by the following 655 formulation:

$$
\begin{gathered}
B A_{i}=\frac{1}{2}\left(\frac{R R M S_{i}-\min (R R M S)}{\max (R R M S)-\min (R R M S)}+\frac{R M E_{i}-\min (R M E)}{\max (R M E)-\min (R M E)}\right) \\
+\frac{S a I_{i}-\min (S a I)}{\max (S a I)-\min (S a I)}
\end{gathered}
$$

656 In this formulation, the three metrics are scaled by their max-min values, and we balanced the 657 classical metrics $R R M S$ and $R M E$ with the new metric SaI. Other formulations could have 658 been used for $B A$ but we privileged the balanced linear formulation that is more robust than 659 other formulations based on single values like min-max values. Due to the small number of 660 experimental data, more sophisticated composite metrics would have been questionable. 661 Following this formulation, the smallest the $B A$, the better is the agreement between 662 experimental dissolution rates and simulated dissolution rates.

Based on the $B A$ metric, only a narrow range of probabilities provided a satisfactory 664 agreement between simulation outputs and experimental data (Fig. 9) and one set of 665 probabilities $\left(\left[P_{M g O M g}=0.99, P_{S i O M g}=0.4 ; P_{S i O S i}=0.0146\right]\right)$ yielded the lowest value of $B A$

$666(B A=0.05)$. This set has been selected to further discuss the outputs of the simulations below, 667 although it is noteworthy that a couple of sets of probabilities also returns similarly low $B A$ 668 values (e.g., the two sets of probabilities $\left[P_{M g O M g}=0.99, P_{S i O M g}=0.25 ; P_{S i O S i}=0.0177\right]$ and $669\left[P_{M g O M g}=0.99, P_{S i O M g}=0.3 ; P_{S i O S i}=0.0212\right]$ correspond to $B A$ values of 0.07 and 0.09 , 
671 (and therefore, of $\Delta E_{S i-O-S i}-\Delta E_{S i-O-M g}$ and $\Delta E_{M g-O-M g}-\Delta E_{S i-O-M g}$ ) values.
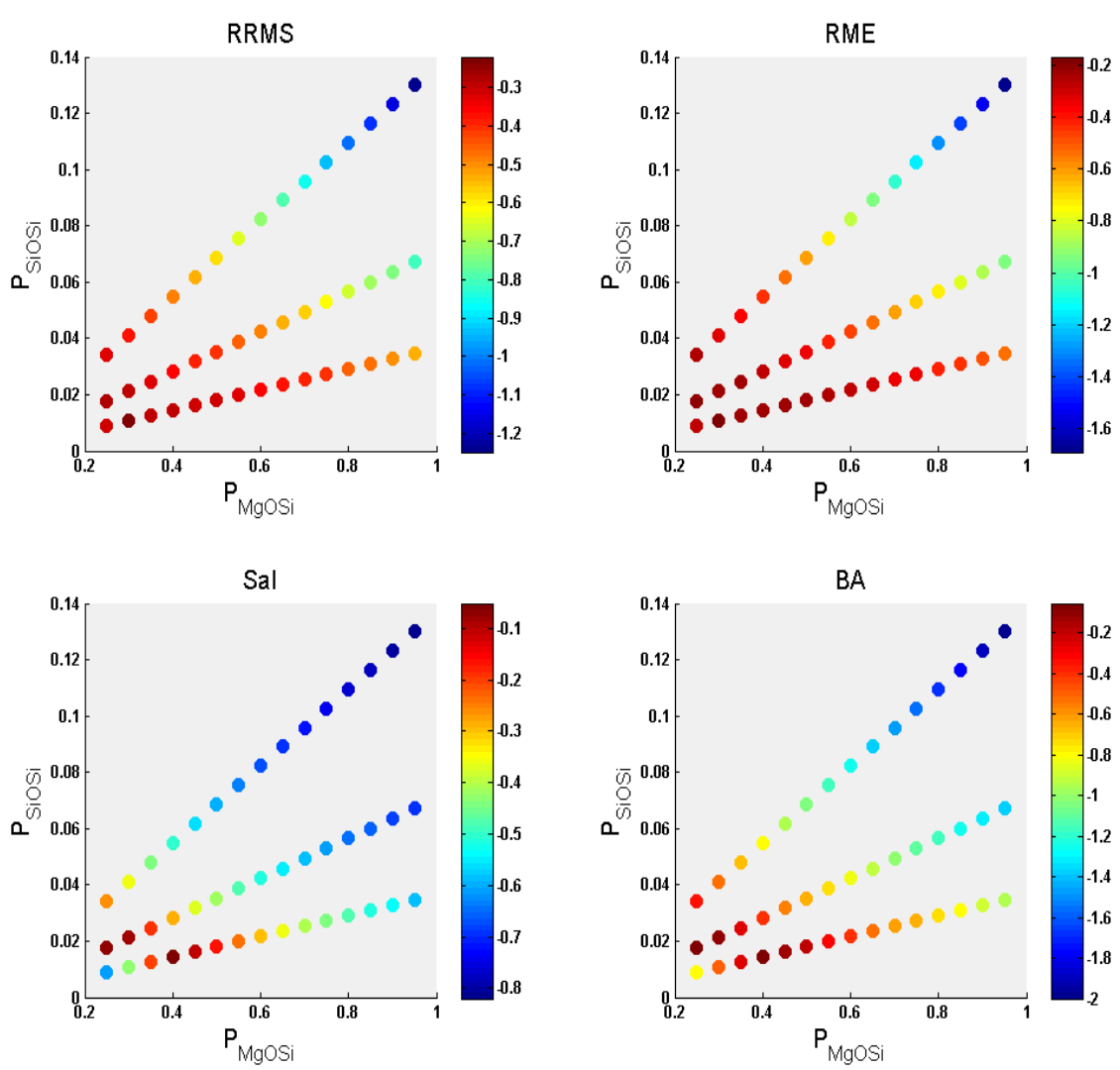

Fig. 9. Color maps of the agreement between modeled and measured dissolution rates in regards to the sets of probabilities that have been tested. The browner the color, the better agreement. See section 4.2 for a description of the RRMS, RME, $S a I$ and $B A$ indices.

The discrepancies between the results of the simulations conducted with and without 678 dislocations are shown in Fig. 8A. As mentioned above, the main impact of the implementation of the right dislocation density for the (100), (010) and (210) faces consists in an inversion between the reactivities of the (210) and (010) faces. Whereas the face-specific

681 dissolution rates observe the following trend without dislocations : $r_{\bmod }^{(100)}<r_{\bmod }^{(210)}<r_{\bmod }^{(010)}<<$ $682 r_{\text {mod }}^{(001)}$, it becomes $r_{\text {mod }}^{(100)}<r_{\text {mod }}^{(010)}<r_{\text {mod }}^{(210)}<<r_{\text {mod }}^{(001)}$ when dislocations are added, in good agreement with the experimental measurements. In detail, the implementation of dislocations increased the dissolution rates of the (210) and (100) faces, while the reactivity of the $(010)$ 
685 face remains unaffected, probably because of the low dislocation density observed on this

686 face. Finally, the outcropping of dislocations at the surface of the (001) face has not been

687 considered, since it was not possible to evidence etch pits on the corresponding samples. Of

688 note, the implementation of dislocations also has an impact on the agreement between

689 simulation outputs and experimental results. Whereas the implementation of dislocations tend

690 to minimize the $R R M S$ and $R M E$ values $(R R M S=22 \%$ and $R M E=13 \%$ with dislocations vs.

$691 R R M S=30 \%$ and $R M E=22 \%$ without dislocations), this also results in a modest increase of

692 the $\operatorname{SaI}(\mathrm{SaI}=0.11$ vs. $S a I=0.05)$, implying that the dissolution rate anisotropy becomes

693 slightly underestimated. Overall, it can be concluded that adding dislocations to the model

694 slightly improves the general agreement between simulation outputs and experimental results

695 in terms of $R R M S$ and $R M E$ but slightly degrades the account for the anisotropy of dissolution

696 rates (increase of the $S a I$ value). However, the $B A$ index remains unaffected $(B A=0.06$ in

697 both cases), which indicates that for this set of probabilities, the simulations conducted with

698 dislocations are statistically equivalent to those run without dislocations.

699 To sum up, the model satisfactorily accounts for enstatite face-specific dissolution 700 rates measured experimentally, using bond-breaking probabilities consistent with what can be

701 inferred from literature. Moreover, adding dislocations to the simulations in proportions that 702 are consistent with the analytical characterizations allows one to reproduce the order of the 703 face-specific dissolution rates observed experimentally.

\subsection{Comparison between observed and modeled etch pits and related implications for}

The improvement of the agreement between modeled and experimental dissolution rates is not the only interesting output resulting from the implementation of dislocations in the

708 simulated crystals. It also offers the possibility to compare the morphology of simulated etch 709 pits developed at the dislocation outcrop to their counterparts revealed by electron microscopy 
on the different faces of enstatite (Fig. 4). This represents an aspect of great interest, as it is

711 regularly searched for as a tracer of weathering conditions ${ }^{78-80}$. previous section) are consistent with those observed experimentally. The simulated and experimentally observed pits are very elongated along the $c$-axis and their minor-axes follow either the [010] (for pits developed on (100) faces) or the [100] (for pits developed on the (010) faces) direction, respectively. These directions also represent symmetry axes for the pits, resulting in the existence of a symmetry point at their center. The TEM characterizations performed on the FIB thin section realized on the altered (010) and (100) faces further indicate that the angle formed by the pit walls with the surface are in good agreement with the outputs of the simulations.

A noticeable difference revealed by the model between the pits developed on the (100) and (010) faces consists in the shape of their bottoms following the $c$-direction (Fig. 7). These differences may be ascribed to the crystallographic structure of enstatite. Indeed, while the deepening of pits formed on the (100) face requires to sequentially intersect Si-rich and $\mathrm{Mg}$ rich planes, the deepening of pits formed on the (010) face entails that the dissolution takes place in a single plane, resulting in a faster opening of the corresponding pits. This may explain why modeled etch pits formed on the (010) face are flat-bottomed in the $c$-direction, as opposed to the pits formed on the (100) face, since the propagation of the dissolution

730 following the $c$-axis will be easier in the case of the (010) face than the one of the (100) face.

731 Supporting this assertion, the sequential removal of $\mathrm{Mg}$ atoms from $\mathrm{Mg}$-planes, which are readily accessible for pits formed on (010) faces, will result in lowering the coordination of $\mathrm{Si}$ atoms in the Si-planes, thereby accelerating the global propagation of the pit along the $c$-axis.

734 Such a mechanism is not possible for pits developed on the (100) face, where the widening of 
a pit involves dissolving Mg- and Si-rich planes sequentially. Finally, it is noteworthy that these differences in terms of pit morphology, which follow from the anisotropic structure of enstatite, also result in a difference of reactivity of the pits themselves, with pits developed on the (010) faces being more effective to enhance enstatite dissolution than those developed on the (100) faces. Finally, TEM observations reveal that etch pits nucleated on the (100) face are flat-bottomed following their minor axis ([010]), a feature that is not accurately reproduced by the model. Possible explanations for this observation include the fact that etch pits revealed experimentally may have investigated at a greater reaction progress than the modeled ones, which result in a widening of the pit in the $b$-direction.

Regarding the modeled pits formed on the (001) face, their main features consist in their narrow subcircular shape $(5 \mathrm{~nm})$ and important depth $(>20 \mathrm{~nm})$. As reported above, the simulations reveal that the diameter of the simulated pits never exceeds $5 \mathrm{~nm}$ because of the gradual and global roughening of the surface, which may explain why no etch pits were observed by VSI, SEM or TEM on the (001) samples altered experimentally. The absence of a continued lateral growth of the pits in the (001) plane also suggests that dislocation etch pits form on the (001) face (if any) have a negligible contribution to the dissolution rate of this face.

The pits that have been simulated on the (210) face are different from the ones simulated on the (100) and (010) faces. Their shape approaches that of a crescent, with one straight edge along the $c$-axis on one side and a curvilinear edge on the other side. This shape is consistent with that revealed experimentally for (210) samples (see Fig. 4), and very similar to the one observed for pits developed on the (110) and (110) faces of diopside by Daval et al. ${ }^{18}$. The topography profile of the pits following the $c$-axis is similar to the one observed on the $(100)$ face, with a deepest point $(\approx 2.0-2.5 \mathrm{~nm})$ located at the center of the pit. The main difference between the pits simulated on this face and those simulated on the (100) and (010) 
faces is revealed when considering the topography profile of the pit following the minor-axis, which is strongly asymmetric. Whereas the angle between the (210) surface and the pit wall at the straight edge is very steep $\left(\theta \approx 95^{\circ}\right)$, the other one is much less sharp $\left(\theta \approx 113^{\circ}\right)$. Although it was not possible to get a FIB foil across a single etch pit nucleated on the (210) face, it is worth mentioning that this asymmetry was also observed for pits developed on the (110) face of diopside (see atomic force microscopy (AFM) measurements in ${ }^{18}$ ). This asymmetry is due to the fact that the direction of the dislocation is not orthogonal to the (210) face. An 767 interesting consequence of this specific geometry is that the entire simulated pit is not visible in Fig. 7, since part of the pit is located below the surface of the face. Such features may correspond to the so-called "etch tubes"77 or "etch tunnels" 81 sometimes reported in the 770 literature, which cannot be imaged using classical surface sensitive techniques such as VSI or 771 AFM.

Finally, the pit geometry revealed by the numerical simulations also has broader 773 consequences for the practical measurement of crystal dissolution rates. As can be seen in Fig. $6 \mathrm{D}$, the dissolution rate of the (210) face based on $\mathrm{Mg}$ release exceeds that calculated using 775 the overall surface topography. Such a "hidden" contribution to crystal reactivity may help 776 explain why face-specific mineral dissolution rates determined from solution chemistry 777 measurements sometimes overestimate dissolution rates estimated using surface sensitive 778 techniques, such as $\mathrm{VSI}^{24}$. Furthermore, considering that the dislocation network in crystals 779 can be connected to the surface as a result of pit opening, intra-crystalline dissolution may 780 occur. A detailed understanding of the solution chemistry within single pits then becomes 781 crucial, since concentration gradients can affect the reactivity of the etch pit ${ }^{78}$. To sum up, the etch pits modeled on (100), (010) and (210) are very similar to the 783 ones observed on enstatite samples. The orientation, shape, and symmetry of the pits are 
correctly predicted by the model, and result from the crystallographic structure of enstatite and orientation of dislocation lines.

786

787

788

789

790

791

792

793

\subsection{Relation between the dissolution regime and the formation of Si-rich surface layers}

As shown in Fig. 6, the transient regime, which is characterized by a nonstoichiometric release of $\mathrm{Mg}$ and $\mathrm{Si}$ atoms and a variable dissolution rate, spans over 7,500 to 8,250 iterations (depending on the considered face) corresponding to $2.7 \pm 1.0$ to $2.9 \pm 1.0$ days, when the best set of probabilities is selected (section 2.3.6). This result suggests that the dissolution rates estimated experimentally for the (100), (010) and (210) faces were actually measured during the steady-state regime, where the dissolution is stoichiometric and the rate is constant, and may explain why the very first VSI measurements of surface retreats conducted on the (100) and (010) faces fall slightly below the regression trend line. Conversely, part of the measurements carried out on the (001) faces might have been performed during the transient regime, although this assertion is not supported experimentally, since the measured surface retreats observe a linear temporal trend. This result is not totally surprising, considering the expected modest evolution of the dissolution rate with time inferred from the numerical outputs of the simulation for this face (Fig. 6), which would imply that any deviation from the linear trend would fall within experimental uncertainties.

From a physical standpoint, the model outputs suggest that the transient regime corresponds to the period where the number of surface atoms increases. The number of atoms at the surface increases by a 2.5-, 2.8-, 3.5-, and 80 fold-factor for the (100), (210), (010) and (001) faces, respectively. After this transient regime, the number of each surface cation reaches a constant value, resulting in a steady-state dissolution rate. Prior to reaching the steady-state regime, the dissolution rates based on $\mathrm{Mg}$ or $\mathrm{Si}$ release have opposite trends: 
while the $\mathrm{Mg}$ release rate decreases, enstatite dissolution rate based on Si release increases with time.

The attainment of a steady-state regime thereby appears intimately connected to the

811 dynamics of Si release, which can be explained by the large differences existing between the

812 detachment rates of $\mathrm{Mg}$ and $\mathrm{Si}$ atoms: the preferential detachment of $\mathrm{Mg}$ atoms will result in a 813 depletion of the first coordination sphere of Si atoms, in turn increasing their release rates.

814 The simultaneous attainment of a constant dissolution rate and a constant number of Si 815 surface atoms for the 4 faces further suggests that the mean coordination of Si surface atoms 816 also reached a steady-state after the transient regime.

817 This divergence in the dynamics of $\mathrm{Si}$ and $\mathrm{Mg}$ release has another important 818 consequence: during the transient regime, the simulations predict that the preferential release 819 of $\mathrm{Mg}$ atoms results in the formation of an $\mathrm{Mg}$-depleted / Si-rich surface layer. According to 820 the simulation outputs, the thickness of the leached layer is 3.8, 6.0, 6.9 and $107 \AA$ for (100), 821 (210), (010), and (001) faces, respectively. Interestingly, the model therefore predicts that 822 thick surface layers should develop on the (001) face, whereas they should be much thinner 823 on $(h k 0)$ faces, which is consistent with the TEM results described in section 3.3 , and the 824 results reported by Daval et al. ${ }^{18}$ for diopside dissolution. However, the model systematically 825 underestimates the actual thickness of the layer, which may be ascribed to the fact that it 826 neither accounts for (i) the spontaneous reorganization of the Mg-depleted layer, such as the 827 condensation of silanol groups, which may be associated to a global variation of the volume 828 of the surface layers, as suggested in previous studies (e.g. ${ }^{82-83}$ ); nor for (ii) the backward 829 reactions of $\mathrm{Si}$ attachment to the surface layer, following the alternative interfacial 830 dissolution-reprecipitation mechanism ${ }^{26,60-61,84}$. Here, and as emphasized in previous kMC 831 studies $^{62}$, the outputs of the model indirectly support that the preferential alkali / alkaline earth 
832

833

834

835

836

837

838

840

841

842

843

844

845

846

847

848

849

850

851

852

853

854

855

depletion during silicate dissolution is limited to the topmost layers of the minerals, and that ASSL formation should, at least partly, result from Si redeposition ${ }^{23}$.

To sum up, the comparison between the experimental data and the simulation outputs suggests that the duration of the transient period is reasonably well reproduced by the model. In addition, the model predicts the formation of Mg-depleted / Si-rich layers, although their actual thickness remains underestimated. This latter result indirectly reveals that certain mechanisms that are not accounted for by the model (e.g. Si attachment reactions; condensation of silanol groups) actually occur over the course of enstatite dissolution.

\section{Conclusions and perspectives}

In this study, we focused on the agreement between the outputs of stochastic atomicscale dissolution simulations and the results obtained on face-specific enstatite dissolution experiments carried out at $90{ }^{\circ} \mathrm{C}$ and $\mathrm{pH} 0$ (rate data and structural observations of the faces). Nearly 200 simulations were conducted to demonstrate that the anisotropy of enstatite dissolution rate can be satisfactorily reproduced using bond-breaking probability ratios (and therefore, activation energy differences) that are consistent with the existing literature regarding the hydrolysis of $\mathrm{Mg}-\mathrm{O}-\mathrm{Mg}, \mathrm{Mg}-\mathrm{O}-\mathrm{Si}$ and $\mathrm{Si}-\mathrm{O}-\mathrm{Si}$ bonds. On the same footing, the model also correctly predicts various face-specific features, such as the orientation, symmetry, and shape of dislocation etch pits. From a physical chemistry standpoint, this agreement gives rise to the following two perspectives with respect to silicate dissolution and the silicate-water interface:

(i) Nowadays, ab initio calculations are generally used to feed kMC simulations (e.g. 9, $\left.{ }^{22,}{ }^{45}\right)$. Conversely, our study suggests that $\mathrm{kMC}$ simulations have the ability to be a powerful tool to constrain a range of activation energies for the hydrolysis of bonds that are not 
available in the current literature, and/or to validate the values resulting from $a b$ initio calculations. For instance, the value of $\Delta E_{M g-O-M g}$ we used was selected from an experimental work $^{55}$, because to the best of our knowledge, no study provided a theoretical value for this parameter. If the agreement between modeled and simulated rates and etch pit geometry is taken for granted, it could be immediately transposed to the diopside structure, for which farfrom-equilibrium rate data already exist ${ }^{18}$, making possible the determination of a possible range for parameters such as $\Delta E_{\mathrm{Mg-O}-\mathrm{Ca}}, \Delta E_{\mathrm{Ca}-\mathrm{O}-\mathrm{Ca}}$ or $\Delta E_{\mathrm{Ca}-\mathrm{O}-\mathrm{Si}}$ (note that ab initio data already exist for this latter parameter, see ${ }^{38}$ ). This will be the subject of an upcoming paper.

(ii) On the same footing, a similar approach could be usefully transposed to other silicate structures for which rate data already exist (see ${ }^{71}$, which report far-from-equilibrium rate data for a series of eight endmember orthosilicate minerals $\left(\mathrm{M}_{2} \mathrm{SiO}_{4}\right)$ which varied only by the nature of the divalent cation $\mathrm{M}$ they contain).

Conversely, we showed that the model underestimates the thickness of ASSLs formed on the various faces of enstatite. In itself, this result already provides insights into the dynamics of the dissolution process, as previously pointed out by Zhang and Lüttge ${ }^{62}$ : thick (i.e., several 10s of nm) ASSLs cannot be formed by a pure leaching mechanism only. This indicates where future $\mathrm{kMC}$ efforts should be directed, as the formation, growth and maturation of such layers are regularly suggested to influence the reactivity of the underlying substrate, at least in $\mathrm{SiO}_{2}(\mathrm{aq})$ rich solutions and mildly acidic $\mathrm{pHs}^{20,31,75-76}$.

\section{Acknowledgements}

We warmly thank G. Morvan and R. Boutin (LHyGeS, Strasbourg) for their help with EBSD and ICP-AES measurements. M. Cabié (CP2M, Aix-Marseille) and T. Dintzer (ICPEES, Strasbourg) are acknowledged for their help with the preparation of the FIB thin sections and 
Strasbourg for funding his $\mathrm{PhD}$ grant.

882

\section{References}

884

885

886

887

888

889

890

891

892

893

894

895

896

897

898

899

900

901

902

903

904

905

906

907

908

909

910

911

912

913

914

915

916

917

918

919

920

921

922

923

1. Huntington, T.; Hooper, R.; Johnson, C.; Aulenbach, B. T.; Cappellato, R.; Blum, A., Calcium Depletion in a Southeastern United States Forest Ecosystem. Soil Science Society of America Journal 2000, 64, 1845-1858.

2. Frugier, P., et al., Son68 Nuclear Glass Dissolution Kinetics: Current State of Knowledge and Basis of the New Graal Model. Journal of Nuclear Materials 2008, 380, 821.

3. Johnson, D. B.; Hallberg, K. B., Acid Mine Drainage Remediation Options: A Review. Science of the Total Environment 2005, 338, 3-14.

4. Brantley, S.; Megonigal, J. P.; Scatena, F.; Balogh-Brunstad, Z.; Barnes, R.; Bruns, M.; Van Cappellen, P.; Dontsova, K.; Hartnett, H.; Hartshorn, A., Twelve Testable Hypotheses on the Geobiology of Weathering. Geobiology 2011, 9, 140-165.

5. Le Hir, G.; Ramstein, G.; Donnadieu, Y.; Godderis, Y., Scenario for the Evolution of Atmospheric Pco(2) During a Snowball Earth. Geology 2008, 36, 47-50.

6. Beaulieu, E.; Godderis, Y.; Donnadieu, Y.; Labat, D.; Roelandt, C., High Sensitivity of the Continental-Weathering Carbon Dioxide Sink to Future Climate Change. Nat Clim Change 2012, 2, 346-349.

7. Nicoleau, L.; Bertolim, M. A., Analytical Model for the Alite (C3s) Dissolution Topography. Journal of the American Ceramic Society 2015.

8. Robin, V.; Wild, B.; Daval, D.; Pollet-Villard, M.; Nonat, A.; Nicoleau, L., Experimental Study and Numerical Simulation of the Dissolution Anisotropy of Tricalcium Silicate. Chem Geol 2018, 497, 64-73.

9. Kurganskaya, I.; Luttge, A., A Comprehensive Stochastic Model of Phyllosilicate Dissolution: Structure and Kinematics of Etch Pits Formed on Muscovite Basal Face. Geochim Cosmochim Ac 2013, 120, 545-560.

10. Brantley, S. L.; Olsen, A. A., 7.3 - Reaction Kinetics of Primary Rock-Forming Minerals under Ambient Conditions A2 - Holland, Heinrich D. In Treatise on Geochemistry (Second Edition), Turekian, K. K., Ed. Elsevier: Oxford, 2014; pp 69-113.

11. Eyring, H., The Activates Complex in Chemical Reactions. Journal of Physical Chemistry 1935, 3, 107-120.

12. Aagaard, P.; Helgeson, H. C., Thermodynamic and Kinetic Constraints on ReactionRates among Minerals and Aqueous-Solutions .1. Theoretical Considerations. Am J Sci 1982, 282, 237-285.

13. Noiriel, C.; Daval, D., Pore-Scale Geochemical Reactivity Associated with Co2 Storage: New Frontiers at the Fluid-Solid Interface. Accounts of Chemical Research 2017, $50,759-768$.

14. Luttge, A.; Arvidson, R. S.; Fischer, C.; Kurganskaya, I., Kinetic Concepts for Quantitative Prediction of Fluid-Solid Interactions. Chem Geol 2019, 504, 216-235.

15. Fischer, C.; Arvidson, R. S.; Lüttge, A., How Predictable Are Dissolution Rates of Crystalline Material? Geochim Cosmochim Ac 2012, 98, 177-185. 
16. Gratz, A. J.; Bird, P.; Quiro, G. B., Dissolution of Quartz in Aqueous Basic Solution, 106-236 ${ }^{\circ}$ : Surface Kinetics of "Perfect" Crystallographic Faces. Geochim Cosmochim Ac 1990, 54, 2911-2922. 17. Godinho, J. R. A.; Piazolo, S.; Evins, L. Z., Effect of Surface Orientation on Dissolution Rates and Topography of Caf2. Geochim Cosmochim Ac 2012, 86, 392-403.

18. Daval, D.; Hellmann, R.; Saldi, G. D.; Wirth, R.; Knauss, K. G., Linking Nm-Scale Measurements of the Anisotropy of Silicate Surface Reactivity to Macroscopic Dissolution Rate Laws: New Insights Based on Diopside. Geochim Cosmochim Ac 2013, 107, 121-134.

931

19. Smith, M. E.; Knauss, K. G.; Higgins, S. R., Effects of Crystal Orientation on the Dissolution of Calcite by Chemical and Microscopic Analysis. Chem Geol 2013, 360-361, $10-21$.

20. Wild, B.; Daval, D.; Guyot, F.; Knauss, K. G.; Pollet-Villard, M.; Imfeld, G., PhDependent Control of Feldspar Dissolution Rate by Altered Surface Layers. Chem Geol 2016, 442, 148-159.

938 21. Pollet-Villard, M.; Daval, D.; Ackerer, P.; Saldi, G. D.; Wild, B.; Knauss, K. G.; Fritz, B., Does Crystallographic Anisotropy Prevent the Conventional Treatment of Aqueous Mineral Reactivity? A Case Study Based on K-Feldspar Dissolution Kinetics. Geochim Cosmochim Ac 2016, 190, 294-308.

22. Kurganskaya, I.; Luttge, A., Kinetic Monte Carlo Approach to Study Carbonate Dissolution. The Journal of Physical Chemistry C 2016, 120, 6482-6492.

23. Daval, D.; Bernard, S.; Rémusat, L.; Wild, B.; Guyot, F.; Micha, J. S.; Rieutord, F.; Magnin, V.; Fernandez-Martinez, A., Dynamics of Altered Surface Layer Formation on Dissolving Silicates. Geochim Cosmochim Ac 2017, 209, 51-69.

24. Perez, A.; Daval, D.; Fournier, M.; Vital, M.; Delaye, J.-M.; Gin, S., Comparing the Reactivity of Glasses with Their Crystalline Equivalents: The Case Study of Plagioclase Feldspar. Geochim Cosmochim Ac 2019, 254, 122-141.

25. Hartman, P.; Perdok, W. G., On the Relations between Structure and Morphology of Crystals. I. Acta Crystallographica 1955, 8, 49-52.

26. Daval, D.; Martinez, I.; Guigner, J. M.; Hellmann, R.; Corvisier, J.; Findling, N.; Dominici, C.; Goffe, B.; Guyot, F., Mechanism of Wollastonite Carbonation Deduced from Micro- to Nanometer Length Scale Observations. Am Mineral 2009, 94, 1707-1726.

27. Kwak, J. H.; Hu, J. Z.; Hoyt, D. W.; Sears, J. A.; Wang, C.; Rosso, K. M.; Felmy, A. R., Metal Carbonation of Forsterite in Supercritical Co2 and H2o Using Solid State 29si, 13c Nmr Spectroscopy. The Journal of Physical Chemistry C 2010, 114, 4126-4134.

28. Gin, S. p.; Guittonneau, C.; Godon, N.; Neff, D.; Rebiscoul, D.; Cabié, M.; Mostefaoui, S., Nuclear Glass Durability: New Insight into Alteration Layer Properties. The Journal of Physical Chemistry C 2011, 115, 18696-18706.

29. Gin, S.; Jollivet, P.; Fournier, M.; Angeli, F.; Frugier, P.; Charpentier, T., Origin and Consequences of Silicate Glass Passivation by Surface Layers. Nat Commun 2015, 6 .

30. Hellmann, R.; Cotte, S.; Cadel, E.; Malladi, S.; Karlsson, L. S.; Lozano-Perez, S.; Cabié, M.; Seyeux, A., Nanometre-Scale Evidence for Interfacial Dissolution-Reprecipitation Control of Silicate Glass Corrosion. Nat Mater 2015, 14, 307-311.

31. Daval, D.; Calvaruso, C.; Guyot, F.; Turpault, M.-P., Time-Dependent Feldspar Dissolution Rates Resulting from Surface Passivation: Experimental Evidence and Geochemical Implications. Earth Planet Sc Lett 2018, 498, 226-236.

32. Rébiscoul, D.; Cambedouzou, J.; Matar Briman, I.; Cabié, M.; Brau, H. P.; Diat, O., Water Dynamics in Nanoporous Alteration Layer Coming from Glass Alteration: An Experimental Approach. The Journal of Physical Chemistry C 2015, 119, 15982-15993. 
982

983

984

985

986

987

988

989

990

991

992

993

994

995

996

997

998

999

1000

1001

1002

1003

1004

1005

1006

1007

1008

1009

1010

1011

1012

1013

1014

1015

1016

1017

1018

1019

1020

33. Xiao, Y.; Lasaga, A. C., Ab Initio Quantum Mechanical Studies of the Kinetics and Mechanisms of Silicate Dissolution: $\mathrm{H}+(\mathrm{H3o}+)$ Catalysis. Geochim Cosmochim Ac 1994, 58, 5379-5400.

34. Pelmenschikov, A.; Strandh, H.; Pettersson, L. G.; Leszczynski, J., Lattice Resistance to Hydrolysis of Si- O- Si Bonds of Silicate Minerals: Ab Initio Calculations of a Single Water Attack onto the (001) and (111) B-Cristobalite Surfaces. The Journal of Physical Chemistry B 2000, 104, 5779-5783.

35. Criscenti, L. J.; Kubicki, J. D.; Brantley, S. L., Silicate Glass and Mineral Dissolution: Calculated Reaction Paths and Activation Energies for Hydrolysis of a Q(3) Si by $\mathrm{H} 30+$ Using Ab Initio Methods. Journal of Physical Chemistry A 2006, 110, 198-206.

36. Morrow, C. P.; Nangia, S.; Garrison, B. J., Ab Initio Investigation of Dissolution Mechanisms in Aluminosilicate Minerals. The Journal of Physical Chemistry A 2009, 113, 1343-1352.

37. Morrow, C. P.; Kubicki, J. D.; Mueller, K. T.; Cole, D. R., Description of Mg2+ Release from Forsterite Using Ab Initio Methods. The Journal of Physical Chemistry C 2010, $114,5417-5428$.

38. Morrow, C. P.; Olsen, A. A.; Kubicki, J. D., Quantum Mechanical Modeling of Hydrolysis and $\mathrm{H} 2 \mathrm{o}-$ Exchange in $\mathrm{Mg}-\mathrm{Ca}-$, and Ni-Silicate Clusters: Implications for Dissolution Mechanisms of Olivine Minerals. Am Mineral 2014, 99, 2303-2312.

39. Lasaga, A. C.; Luttge, A., Mineralogical Approaches to Fundamental Crystal Dissolution Kinetics. Am Mineral 2004, 89, 527-540.

40. Devreux, F.; Ledieu, A.; Barboux, P.; Minet, Y., Leaching of Borosilicate Glasses. Ii. Model and Monte-Carlo Simulations. Journal of Non-Crystalline Solids 2004, 343, 13-25.

41. Zhang, L.; Lüttge, A., Al, Si Order in Albite and Its Effect on Albite Dissolution Processes: A Monte Carlo Study. Am Mineral 2007, 92, 1316-1324.

42. Zhang, L.; Lüttge, A., Aluminosilicate Dissolution Kinetics: A General Stochastic Model. The Journal of Physical Chemistry B 2008, 112, 1736-1742.

43. Meakin, P.; Rosso, K. M., Simple Kinetic Monte Carlo Models for Dissolution Pitting Induced by Crystal Defects. The Journal of Chemical Physics 2008, 129, 204106.

44. Cailleteau, C.; Angeli, F.; Devreux, F.; Gin, S.; Jestin, J.; Jollivet, P.; Spalla, O., Insight into Silicate-Glass Corrosion Mechanisms. Nature Materials 2008, 7, 978-983.

45. Kurganskaya, I.; Luttge, A., Kinetic Monte Carlo Simulations of Silicate Dissolution: Model Complexity and Parametrization. The Journal of Physical Chemistry C 2013, 117, 24894-24906.

46. Briese, L.; Arvidson, R. S.; Luttge, A., The Effect of Crystal Size Variation on the Rate of Dissolution - a Kinetic Monte Carlo Study. Geochim Cosmochim Ac 2017, 212, 167175.

47. de Assis, T. A.; Aarão Reis, F. D. A., Dissolution of Minerals with Rough Surfaces. Geochim Cosmochim Ac 2018, 228, 27-41.

48. Lüttge, A.; Arvidson, R. S.; Fischer, C., A Stochastic Treatment of Crystal Dissolution Kinetics. Elements 2013, 9, 183-188.

49. Di Lorenzo, F.; Ruiz-Agudo, C.; Ibañez-Velasco, A.; Gil-San Millán, R.; Navarro, J. A.; Ruiz-Agudo, E.; Rodriguez-Navarro, C., The Carbonation of Wollastonite: A Model Reaction to Test Natural and Biomimetic Catalysts for Enhanced Co2 Sequestration. Minerals 2018, 8, 209.

50. van der Lee, J.; De Windt, L., Chess Tutorial and Cookbook. Updated for Version 3.0.: Paris, 2002; Vol. Manual Nr. LHM/RD/02/13, p 116.

51. Lüttge, A.; Bolton, E. W.; Lasaga, A. C., An Interferometric Study of the Dissolution Kinetics of Anorthite; the Role of Reactive Surface Area. Am J Sci 1999, 299, 652-678. 
1021 52. Lasaga, A. C.; Blum, A. E., Surface Chemistry, Etch Pits and Mineral-Water 1022 Reactions. Geochim Cosmochim Ac 1986, 50, 2363-2379.

1023 53. Cailleteau, C.; Devreux, F.; Spalla, O.; Angeli, F.; Gin, S., Why Do Certain Glasses

1024

1025

1026

1027

1028

1029

1030

1031

1032

1033

1034

1035

1036

1037

1038

1039

1040

1041

1042

1043

1044

1045

1046

1047

1048

1049

1050

1051

1052

1053

1054

1055

1056

1057

1058

1059

1060

1061

1062

1063

1064

1065

1066

1067

1068

1069

1070 with a High Dissolution Rate Undergo a Low Degree of Corrosion? The Journal of Physical Chemistry C 2011, 115, 5846-5855.

54. Hugh-Jones, D. A.; J., A. R., A Compressional Study of Mgsio3 Orthoenstatite up to 8.5 Gpa. Am Mineral 1994, 79, 405-410.

55. Jordan, G.; Rammensee, W., Dissolution Rates and Activation Energy for Dissolution of Brucite (001) : A New Method Based on the Microtopography of Crystal Surfaces. Geochim Cosmochim Ac 1996, 60, 5055-5062.

56. Gilman, J. J.; Johnston, W. G.; Sears, G. W., Dislocation Etch Pit Formation in Lithium Fluoride. Journal of Applied Physics 1958, 29, 747-754.

57. Skrotzki, W., Defect Structure and Deformation Mechanisms in Naturally Deformed Augite and Enstatite. Tectonophysics 1994, 229, 43-68.

58. Bortz, A. B.; Kalos, M. H.; Lebowitz, J. L., A New Algorithm for Monte Carlo Simulation of Ising Spin Systems. Journal of Computational Physics 1975, 17, 10-18.

59. Petit, J. C.; Dellamea, G.; Dran, J. C.; Schott, J.; Berner, R. A., Mechanism of Diopside Dissolution from Hydrogen Depth Profiling. Nature 1987, 325, 705-707.

60. Ruiz-Agudo, E.; Putnis, C. V.; Rodriguez-Navarro, C.; Putnis, A., Mechanism of Leached Layer Formation During Chemical Weathering of Silicate Minerals. Geology 2012, 40, 947-950.

61. Hellmann, R.; Wirth, R.; Daval, D.; Barnes, J.-P.; Penisson, J.-M.; Tisserand, D.; Epicier, T.; Florin, B.; Hervig, R. L., Unifying Natural and Laboratory Chemical Weathering with Interfacial Dissolution-Reprecipitation: A Study Based on the Nanometer-Scale Chemistry of Fluid-Silicate Interfaces. Chem Geol 2012, 294-295, 203-216.

62. Zhang, L.; Luettge, A., Theoretical Approach to Evaluating Plagioclase Dissolution Mechanisms. Geochim Cosmochim Ac 2009, 73, 2832-2849.

63. Berner, R. A.; Sjoberg, E. L.; Velbel, M. A.; Krom, M. D., Dissolution of Pyroxenes and Amphiboles During Weathering. Science 1980, 207, 1205-1206.

64. Velbel, M. A.; Barker, W. W., Pyroxene Weathering to Smectite: Conventional and Cryo-Field Emission Scanning Electron Microscopy, Koua Bocca Ultramafic Complex, Ivory Coast. Clays and Clay Minerals 2008, 56, 112-127.

65. Phillips-Lander, C. M.; Fowle, D. A.; Taunton, A.; Hernandez, W.; Mora, M.; Moore, D.; Shinogle, H.; Roberts, J. A., Silicate Dissolution in Las Pailas Thermal Field: Implications for Microbial Weathering in Acidic Volcanic Hydrothermal Spring Systems. Geomicrobiology Journal 2014, 31, 23-41.

66. Olsen, T. S.; Kohlstedt, D. L., Analysis of Dislocations in Some Naturally Deformed Plagioclase Feldspars. Phys Chem Miner 1984, 11, 153-160.

67. Pollet-Villard, M.; Daval, D.; Fritz, B.; Knauss, K. G.; Schäfer, G.; Ackerer, P., Influence of Etch Pit Development on the Surface Area and Dissolution Kinetics of the Orthoclase (001) Surface. Chem Geol 2016, 447, 79-92.

68. Oelkers, E. H.; Schott, J., An Experimental Study of Enstatite Dissolution Rates as a Function of $\mathrm{Ph}$, Temperature, and Aqueous $\mathrm{Mg}$ and Si Concentration, and the Mechanism of Pyroxene/Pyroxenoid Dissolution. Geochim Cosmochim Ac 2001, 65, 1219-1231.

69. Blum, A.; Lasaga, A., Role of Surface Speciation in the Low-Temperature Dissolution of Minerals. Nature 1988, 331, 431-433.

70. Fischer, C.; Luttge, A., Beyond the Conventional Understanding of Water-Rock Reactivity. Earth Planet Sc Lett 2017, 457, 100-105.

71. Casey, W. H.; Westrich, H. R., Control of Dissolution Rates of Orthosilicate Minerals by Divalent Metal Oxygen Bonds. Nature 1992, 355, 157-159. 
1071 72. Turpault, M. P.; Trotignon, L., The Dissolution of Biotite Single-Crystals in Dilute 1072 Hno3 at 24-Degrees-C - Evidence of an Anisotropic Corrosion Process of Micas in Acidic 1073 Solutions. Geochim Cosmochim Ac 1994, 58, 2761-2775.

1074 73. Burch, T. E.; Nagy, K. L.; Lasaga, A. C., Free Energydependence of Albite 1075 Dissolution Kinetics at $80^{\circ} \mathrm{C}$ and $\mathrm{Ph}$ 8.8. Chem Geol 1993, 105, 137-162.

1076 74. Lasaga, A. C.; Luttge, A., Variation of Crystal Dissolution Rate Based on a 1077 Dissolution Stepwave Model. Science 2001, 291, 2400-2404.

1078 75. Saldi, G. D.; Daval, D.; Guo, H.; Guyot, F.; Bernard, S.; Le Guillou, C.; Davis, J. A.; 1079 Knauss, K. G., Mineralogical Evolution of Fe-Si-Rich Layers at the Olivine-Water Interface 1080 During Carbonation Reactions. Am Mineral 2015, 100, 2655-2669.

1081 76. Wild, B.; Imfeld, G.; Guyot, F.; Daval, D., Early Stages of Bacterial Community 1082 Adaptation to Silicate Aging. Geology 2018, 46, 555-558.

1083 77. Brantley, S. L.; Crane, S. R.; Crerar, D. A.; Hellmann, R.; Stallard, R., Dissolution at 1084 Dislocation Etch Pits in Quartz. Geochim Cosmochim Ac 1986, 50, 2349-2361.

1085 78. Bouissonnié, A.; Daval, D.; Marinoni, M.; Ackerer, P., From Mixed Flow Reactor to 1086 Column Experiments and Modeling: Upscaling of Calcite Dissolution Rate. Chem Geol 2018, 1087 487, 63-75.

1088 79. Velbel, M. A., Dissolution of Olivine During Natural Weathering. Geochim 1089 Cosmochim Ac 2009, 73, 6098-6113.

1090 80. Phillips-Lander, C. M.; Legett, C.; Madden, A. S. E.; Madden, M. E. E., Can We Use 1091 Pyroxene Weathering Textures to Interpret Aqueous Alteration Conditions? Yes and No. Am 1092 Mineral 2017, 102, 1915-1921.

1093 81. Gratz, A. J.; Bird, P., Quartz Dissolution: Negative Crystal Experiments and a Rate 1094 Law. Geochim Cosmochim Ac 1993, 57, 965-976.

1095 82. Weissbart, E. J.; Rimstidt, D. J., Wollastonite: Incongruent Dissolution and Leached 1096 Layer Formation. Geochim Cosmochim Ac 2000, 64, 4007-4016.

1097 83. Schott, J.; Pokrovsky, O. S.; Spalla, O.; Devreux, F.; Gloter, A.; Mielczarski, J. A., 1098 Formation, Growth and Transformation of Leached Layers During Silicate Minerals 1099 Dissolution: The Example of Wollastonite. Geochim Cosmochim Ac 2012, 98, 259-281.

1100 84. Hellmann, R.; Penisson, J.-M.; Hervig, R. L.; Thomassin, J.-H.; Abrioux, M.-F., An 1101 Eftem/Hrtem High-Resolution Study of the near Surface of Labradorite Feldspar Altered at 1102 Acid Ph: Evidence for Interfacial Dissolution-Reprecipitation. Phys Chem Miner 2003, 30, 1103 192-197. 